\author{
Abramo Dentilli \\ (dottore di ricerca in Giurisprudenza dell’Università degli Studi di Padova)
}

\title{
Il De civitate Dei di Agostino e la sua influenza sul processo di secolarizzazione dello Stato *
}

\author{
Augustine's De civitate Dei and its influence \\ on the process of secularization of the State
}

\begin{abstract}
Is justice essential to State? Augustine, in the fourth book of the City of God, starts with a strict idea of State, but then widens the definition: he grants that also an unjust - not based on the real God - State may be a real State. This option seems to be prominent in the process of secularization enacted in the last centuries, but it's also connected to other matter: the predestination, the identification (or not) between the City of God and the Church, and so on. Methodologically, I tried to read what Augustine really wrote and not what others said about his works.
\end{abstract}

SOMMARIO: 1. Premessa - 2. Il libro IV come introduzione al tema - 3. I magna latrocinia - 4. Lo svolgimento logico della tesi agostiniana sul rapporto tra Stato e giustizia - 5. Cristo come unico criterio per la giustizia/virtù/felicità - 6. Il libro XIX come allargamento dei confini della legittimità dello Stato -7 . Le due civitates - 8 . L'assetto delle due città nel saeculum - 9. L'identificazione della CD con la Chiesa 10. La predestinazione quale criterio di ascrizione alle due civitates - 11. Il DcD come strumento politico - 12. Una conseguenza imprevedibile (?): la secolarizzazione - 13 . Conclusione.

\section{1 - Premessa}

Il presente scritto ${ }^{1}$ risulta l'ampliamento e l'approfondimento dello studio

* Contributo sottoposto a valutazione.

1 Si precisa che tutte le citazioni delle diverse opere agostiniane sono tratte dalle edizioni critiche riportate nella collana CCSL (= Corpus Christianorum, Series Latina), a eccezione di quanto non ancora ivi edito. In particolare, il $D c D$ è contenuto nei volumi XLVII-XVLIII (AURELII AUGUSTINI, Opera, p. XIV, 1-2, De Civitate Dei, Brepols, Turnholti, MCMLV), ove è riprodotta la quarta edizione teubneriana curata da $B$. DOMBART et A. KALB nel 1928-1929. I riferimenti non tratti dal CCSL sono identificabili grazie alla sigla della diversa opera di provenienza, collocata subito dopo la citazione: BA (= Bibliothèque Augustinienne. CEuvres de Saint Augustin); CSEL (= Corpus Scriptorum 
svolto in relazione al libro IV del $D c D$ di Agostino $^{2}$. Originariamente, infatti, ci si era limitati ad affrontare il tema della giustizia rispetto al così detto magnum latrocinium: quest'ultimo argomento è noto anche al di fuori della cerchia degli studi specialistici e spesso viene usato in modo improprio; perciò, il primo intento di chi scrive è stato quello di rendere per così dire - giustizia al concetto di giustizia in Agostino. Eppure, riconsiderando le prime acquisizioni, ben presto è emerso che quanto trattato nel libro IV andava inserito in modo sistematico rispetto a tutta l'Opera e anche a tutto il pensiero dell'Ipponense; così, estendendo il campo dello studio, il tema della giustizia è risultato dipanarsi per tutto il DcD.

Non solo. Si sono presentati all'attenzione anche altri argomenti apparentemente alieni, in realtà ben saldati tra di loro, quali quello del rapporto tra civitas Dei e civitas diaboli, quello della predestinazione, etc. Lentamente, si è potuto appurare che il tema della giustizia non può essere considerato a sé stante, bensì deve essere letto proprio in relazione a una visione organica del pensiero agostiniano.

Il presente elaborato ricalca il suddetto sviluppo. Principiando dal contenuto del libro IV, ci si è inoltrati nell'analisi del rapporto tra giustizia e Stato ${ }^{3}$, così come si svolge (ed evolve) nel corso dell'Opera.

Ecclesiasticorum Latinorum); PL (= Patrologiae Cursus Completus, Series Latina). Si precisa, altresì, che i titoli delle opere agostiniane sono abbreviati secondo 1'uso in C. MAYER et AlII (eds.), Augustinus-Lexikon, Schwabe \& Co., Basel, I, 1986-1994, pp. XLIII-XLV. Onde evitare inutili ripetizioni, $D c D$ indica l'opera De civitate Dei nel corpo del testo e in generale nello scritto. CD, invece, sta per civitas Dei, da intendersi come l'oggetto dell'Opera (non l'Opera stessa, che si cita con ciu.), mentre CS sta per civitas diaboli.

2 In generale, sul DcD, e pluribus cfr. L. ALICI, Introduzione, in AURELIO AGOSTINO, La città di Dio. Introduzione, traduzione, note e appendici di L. ALICI, Rusconi, Milano, 1984, nr. 3, pp. 13-17; A. TRAPÈ, S. Agostino. L'uomo, il pastore, il mistico, Esperienze, Fossano, 1976, capp. XXIX s.; É. GILSON, Les métamorphoses de la cité de Dieu, Vrin, Paris, 2005, 2a ed. (1 ${ }^{\text {a }}$ ed. 1952), traduzione italiana a cura di M. BORGHESI, Le metamorfosi della Città di Dio, Cantagalli, Siena, 2010, I, pp. 72-78; R. BODEI, Ordo amoris. Conflitti terreni e felicità celeste, il Mulino, Bologna, 1991, Introduzione, I, pp. 20-24, e III, pp. 43-45, nonché cap. V, Nel mondo, pp. 189-203.

${ }^{3}$ Non si affronta qui la questione circa l'utilizzabilità, nel mondo antico, del concetto di 'Stato'. Significative paiono le seguenti parole: "Cosa assai notevole, il termine stesso di Stato è apparso solo nel corso della storia moderna; la nozione di Stato era implicitamente contenuta nell'antico concetto di città ( $\pi$ ó $\lambda \iota^{\varsigma}$, civitas, che significava essenzialmente corpo politico) e più ancora nel concetto romano dell'Impero; ma non fu mai esplicitamente individuata nell'antichità" (J. MARITAIN, L'homme et l'Etat, Presses Universitaires de France, Paris, 1965, 2a ed. [1 ${ }^{\text {a }}$ ed. in inglese: 1951], traduzione italiana di 
Successivamente, si sono approfondite alcune tematiche emerse in modo incidentale nel corso dello studio, in particolare il rapporto tra le due civitates e la questione dell'identificazione tra $C D$ e Chiesa. Infine, si è cercato di verificare le conseguenze delle idee agostiniane nel corso dei secoli.

Chiaramente, non si ha alcuna pretesa di completezza, né quanto allo studio del materiale disponibile, né quanto alle possibili analisi. In particolare, si è scelto di limitare l'apporto della dottrina, prediligendo la lettura diretta del $D c D$ e integrando, se mai, con lo studio di passi significativi contenuti in altre opere del Vescovo. Il presente elaborato figura, piuttosto, come una rapida incursione nella sconfinata regio del pensiero di Agostino ${ }^{4}$.

\section{2 - Il libro IV come introduzione al tema ${ }^{5}$}

Nell'economia del $D c D$, il libro IV si presenta come ancora interamente orientato a contrastare le critiche pagane al cristianesimo e, nella fattispecie, la religiosità politeistica6; viene scritto da Agostino dopo che i

L. Frattini, L'uomo e lo Stato, Vita e Pensiero, Milano, 1982, I. Il popolo e lo Stato, nr. 5, p. 19).

${ }^{4}$ Va da sé che le risultanze del presente studio non esprimono le opinioni di chi scrive - specialmente per quanto riguarda il tema della predestinazione -, bensì costituiscono il frutto dell'analisi del pensiero dell'Ipponense.

${ }^{5}$ In generale, sul contenuto di tale libro, cfr. G.J.P. O'DALY, Ciuitate dei (De - ), in C. MAYER et AliI (eds.), Augustinus-Lexikon, cit., nr. 7.a), p. 985 s.; G. CATAPANO, Agostino, Carocci, Roma, 2010, VII, p. 196 s.

6 A tale proposito, Agostino effettua due precisazioni fondamentali. Innanzitutto: "La religione politica non ha alcuna verità. Essa poggia su una canonizzazione della consuetudine contro la verità" (J. RATZINGER, Die Einheit der Nationen. Eine Vision der Kirchenväter, Salzburg-München 1971, traduzione italiana di G. COLOMBI, L'unità delle nazioni. Una visione dei Padri della Chiesa, Morcelliana, Brescia, 2009, 2a ed., 3.I.1, p. 79). «[...] secondo la concezione romana la religione è una istituzione dello Stato, quindi una sua funzione, e come tale subordinata ad esso. Non è un assoluto il quale sia indipendente dagli interessi dei gruppi che lo rappresentano, ma è un valore strumentale rispetto allo "Stato" assoluto. Secondo la concezione cristiana, per contro, nella religione non si tratta di consuetudine ma di verità, che è assoluta, che quindi non viene istituita dallo Stato, ma ha istituito per se stessa una nuova comunità, la quale abbraccia tutti quanti vivono della verità di Dio» (J. RATZINGER, Die Einheit der Nationen, cit., p. 81 s.). In secondo luogo: «La religione politica dei Romani non ha alcuna verità, ma al di sopra di essa esiste una verità, e tale verità è che l'asservimento dell'uomo a consuetudini ostili alla verità lo pone in balìa delle potenze antidivine, che la fede cristiana nomina demoni. 
primi tre erano già stati diffusi ${ }^{7}$ e ciò spiega l'esigenza di collocare, in apertura del testo, una sorta di 'riassunto delle puntate precedenti' ${ }^{8}$. Per la precisione, l'Autore esordisce ribadendo la dannosità del politeismo e l'innocenza del cristianesimo, rispetto ai mali che affliggono Roma9; poi, prosegue affermando che gli dei non hanno evitato ai Quiriti né i mali morali ${ }^{10}$ né i mali fisici ${ }^{11}$.

Conclusa la ricapitolazione, Agostino dichiara di voler verificare se veramente i successi dell'Urbe fossero riconducibili alle divinità pagane, ma, prima, effettua una distinzione tra vero e falso successo, ricordando come la gloria di Roma, in realtà, è sempre stata minata dalla cruenta cupiditas che imponeva costantemente agli individui di essere in

[...] In ciò sta la vera profondità a cui scende la liberazione cristiana e la libertà conquistata in essa: liberando dalla consuetudine affranca da un potere, che l'uomo ha lui stesso dapprima creato, ma che di gran lunga si è levato al di sopra del suo capo e ora è signore su di lui; è divenuto un potere oggettivo, indipendente da lui, breccia d'invasione da parte della potenza del male come tale, che lo sopraffà, cioè dei "demoni"» (J. RATZINGER, Die Einheit der Nationen, cit., 3.I.2, p. 82 s.). Insomma, merito del sacrificio di Cristo è che "[...] elimina il culto politico opposto alla verità e al posto di esso, che è culto dei demoni, mette l'unico universale servizio alla verità, che è la libertà" (J. RATZINGER, Die Einheit der Nationen, cit., p. 84).

7 Per Alici, si può racchiudere la stesura del DCD tra il 412 e il 427 (cfr. L. ALICI, Introduzione, cit., nr. 4, p. 19), mentre per Trapè tra l'inizio del 413 e il 426-427 (cfr. A. TRAPÈ, Introduzione. Teologia, in SANT'AGOSTINO, La Città di Dio, I (Libri I-X), Città Nuova, Roma, 1978, I.1.4, pp. XVI-XVII). Per Fortin, l'Opera venne scritta, a intervalli, tra il 413 e il 427 (cfr. E.L. FORTIN, Civitate Dei, De, in A.D. FitZGERAld [ed.], Agostino. Dizionario enciclopedico, Città Nuova, Roma, 2007, p. 408). Per Sloan, il $D c D$ venne iniziato attorno al 412-413 e finito entro il 426-427 (cfr. M.C. SLOAN, De civitate Dei, in K. PollmanN et AliI [eds.], The Oxford Guide to the Historical Reception of Augustine, Oxford University Press, Oxford, 2013, I, p. 255). Secondo Catapano, i primi 3 libri vennero scritti entro il 13 settembre 413; il IV e il V vennero iniziati all'avvicinarsi della Quaresima del 415 e finiti entro il medesimo anno; verso il 418 erano già scritti i libri fino al XIII ed era in corso di redazione il XIV; l'Opera doveva essere finita ormai quando veniva scritto il II libro delle Retractationes (cfr. G. CATAPANO, Agostino, cit., VII, p. 193). O'Daly non esclude una datazione, per i primi tre libri, tra la fine del 413 e il 414 (cfr. G.J.P. O'DALY, Ciuitate dei (De - ), cit., nr. 2, p. 973 s.), mentre la conclusione dell'Opera sarebbe da ravvisare entro il 426/427 (cfr. G.J.P. O'DALY, Ciuitate dei (De - ), cit., p. 974); il medesimo Autore ritiene che i libri IV e V vennero iniziati nel 415 e completati, al più tardi, lo stesso anno (cfr. G.J.P. O'DALY, Ciuitate dei (De - ), cit., p. 974).

${ }^{8}$ Cfr. G.J.P. O'DALY, Ciuitate dei (De - ), cit., p. 974.

${ }_{9}^{9} \mathrm{Cfr}$. ciu., IV, 1, che sunteggia quanto esposto in ciu., I.

${ }^{10}$ Cfr. ciu., IV, 2: trattasi di mali "quae uel sola uel maxima deputanda sunt" e che sono stati esaminati in ciu., II.

${ }^{11}$ Cfr. ciu., IV, 2. 
apprensione per le conquiste fatte e di bramare nuove guerre ${ }^{12}$. Ed è in tale contesto che, dopo altre considerazioni, si inserisce il passo del così detto magnum latrocinium.

\section{3 - I magna latrocinia}

"Remota itaque iustitia quid sunt regna nisi magna latrocinia? quia et latrocinia quid sunt nisi parua regna? Manus et ipsa hominum est, imperio principis regitur, pacto societatis astringitur, placiti lege praeda diuiditur. Hoc malum si in tantum perditorum hominum accessibus crescit, ut et loca teneat sedes constituat, ciuitates occupet populos subiuget, euidentius regni nomen adsumit, quod ei iam in manifesto confert non dempta cupiditas, sed addita impunitas. Eleganter enim et ueraciter Alexandro illi Magno quidam comprehensus pirata respondit. Nam cum idem rex hominem interrogaret, quid ei uideretur, ut mare haberet infestum, ille libera contumacia: Quod tibi, inquit, ut orbem terrarum; sed quia $<\mathrm{id}>$ ego exiguo nauigio facio, latro uocor; quia tu magna classe, imperator"13.

Questo passo è già stato oggetto di studio ${ }^{14}$, ma non è raro trovare una sua volgarizzazione che non rende giustizia al vero pensiero di Agostino e, anzi, lo banalizza: capita, cioè, di trovare una sorta di identità tra lo Stato - specialmente quello romano - e una banda di briganti, per cui è passata l'idea dell'Ipponense come ostile e sprezzante nei confronti dell'Urbe ${ }^{15}$. Ecco perché pare opportuno analizzare tale passo.

${ }^{12}$ Cfr. ciu., 3. Sul tema della vera o falsa felicità, cfr. infra, par. 5.

${ }^{13} \mathrm{Ciu} ., \mathrm{IV}, 4$.

${ }^{14}$ Cfr., e pluribus, G. CATAPANO, La giustizia nella sfera pubblica secondo Agostino di Ippona. Attualità di un Padre della Chiesa, in Atti dell'Accademia "San Marco" di Pordenone, 20 (2018), nr. 2, p. 87 s.

${ }^{15}$ E pluribus: "Sant'Agostino paragonava la storia romana alle vicende di una banda di predoni" (E. FROMM, To Have or to Be?, Harper \& Row, New York, 1976, traduzione italiana a cura di F. SABA SARDI, Avere o essere?, Mondadori, Milano, 1977, 3.VII, p. 185 s.); «Gli stati, in fondo, potrebbero essere anch'essi, secondo il famoso detto di sant'Agostino, "magna latrocina"» (N. BOBBIO, Etica e politica [1994], in IDEM, Etica e politica. Scritti di impegno civile, Mondadori, Milano, 2009, p. 596). Vi è anche chi, come Prezzolini, riflette proprio sul passo in questione, finendo per equiparare i regna ai latrocinia, senza alcun riferimento alla giustizia (cfr. G. PREZZOLINI, Cristo e/o Machiavelli. Assaggi sopra il pessimismo cristiano di sant'Agostino e il pessimismo naturalistico di Machiavelli, Rusconi, Milano, 1971, pp. 31-32, 56-57, 89. Ma va riconosciuto che tale posizione nasce dalla convinzione che non vi possa essere giustizia sulla terra: cfr. G. PREZZOLINI, Cristo e/o Machiavelli, cit., p. 109; in generale sulla genesi delle riflessioni in tale Opera, dovuta a un 
Innanzitutto, l'Autore non effettua alcuna asserzione apodittica, bensì esordisce ponendo una condizione: Remota itaque iustitia. Si tratta di un ablativo assoluto traducibile in molti modi ${ }^{16}$, ma che, comunque, vincola la comprensione di quanto segue subito dopo (quid sunt regna nisi magna latrocinia?).

Dunque, pare inesatto equiparare automaticamente i regna alle grandi bande di briganti e, a fortiori, estendere ciò, altrettanto automaticamente, a Roma. Agostino non ha alcun livore nei confronti dell'Urbe: le sue critiche sono dirette a Roma non in quanto Roma, bensì in quanto aggregazione politica priva della giustizia. Certo, si potrebbe obiettare che, dopo qualche riga, l'Autore passa a considerare le vicende dei Quiriti da Romolo in poi ${ }^{17}$ e che, già nel libro II, aveva asserito che l'ingiustizia aveva dominato l'Urbe sin dall'origine, non potendosi, dunque, parlare di vero Stato romano ${ }^{18}$; ma ciò non toglie che sia scorretto banalizzare il pensiero contenuto nel passo in analisi, riducendolo a una mera asserzione apodittica.

Proseguendo nella lettura, si nota come Agostino ribalti il punto di vista, per esplicitare il suo ragionamento: quia et latrocinia quid sunt nisi parua regna?. Infatti, mancante la giustizia, non c'è alcuna differenza tra gli Stati ${ }^{19}$ e le bande di briganti: per la precisione, le aggregazioni di criminali non sono altro che piccoli Stati, così come gli Stati non sono altro che grandi aggregazioni di criminali, sempre se manca la giustizia ${ }^{20}$.

Quindi, si può dire che l'Autore abbia una visione negativa delle aggregazioni umane? In realtà, non si può totalmente demonizzare l'esistenza in sé dei singoli Stati. Anzi, lo stesso Ipponense riconosce un

certo scetticismo nei confronti della politica, cfr. G. PREZZOLINI, Manifesto dei conservatori, Edizioni di storia e letteratura, Roma, 2014, II, p. 68 s.).

16 "Una volta che si è rinunciato alla giustizia" (AURELIO AGOSTINO, La città di Dio, cit., p. 221), oppure "Se non è rispettata la giustizia" (SANT'AGOSTINO, La Città di Dio, cit., p. 257), oppure "Allontanata la giustizia" (G. CATAPANO, Agostino, cit., p. 196). Benedetto XVI traduce più liberamente, lasciando, però, impregiudicato il senso: "Togli il diritto" (BENEDETTO XVI, Discorso al Parlamento federale tedesco, Berlino 22 novembre 2011, in La legge di re Salomone. Ragione e diritto nei discorsi di Benedetto XVI, a cura di M. CARTABIA, A. SIMONCINI, BUR, Milano, 2013, p. 245).

${ }^{17} \mathrm{Cfr}$. ciu., IV, 5.

${ }^{18}$ Su ciò, cfr. infra, par. 4.

19 'Stati' in senso improprio, quindi: non a caso, Agostino usa regna e non res publicae.

${ }^{20}$ Si noti il continuo gioco di parallelismi: tra magna latrocinia e parua regna, così come tra dempta cupiditas e addita inpunitas, tra mare e orbem terrarum, tra latro e imperator, tra exiguo nauigio e magna classe (cfr. ciu., IV, 4). 
ruolo provvidenziale nella divisione dell'Orbe in vari regna: "Prorsus diuina prouidentia regna constituuntur humana"21.

Di più, l'Autore esplicita anche che tale azione divina riguarda tanto i buoni che i cattivi: "[...] Deus, ipse dat regna terrena et bonis et malis"22, per cui Ratzinger finisce per ravvisare, qui, un'evoluzione di pensiero, rispetto alle posizioni di Origene ${ }^{23}$. Si potrebbe dire che lo Stato, per quanto ingiusto, risulta, per Agostino, da tollerare, nella misura in cui esso si limita a essere strumentale rispetto a un fine ${ }^{24}$.

Inoltre, l'Autore sembra preludere già a una visione più laica dell'entità politica, laddove si limita a constatare che ogni latrocinium condivide gli stessi elementi costitutivi del regnum: infatti, vi sono uomini, che, sotto la guida di un capo e vincolati da un patto, si spartiscono il bottino secondo l'accordo. L'eventuale successo della banda, con l'allargamento della sfera di controllo criminale, rispetto a luoghi e/o persone, rende ancora più evidente l'attribuibilità della denominazione di regnum: non perché è calata l'illiceità degli scopi, bensì perché è cresciuta l'impunità della condotta, proprio grazie al buon fine delle imprese ${ }^{25}$.

Quindi, alla base delle aggregazioni umane non è necessario che vi sia la giustizia: basta che le persone condividano un fine, per far sì che si formino centri di potere più o meno estesi. Ma pare potersi dire anche che l'eventuale corruzione di una collettività (astrattamente) giusta non comporta necessariamente la venuta meno di quest'ultima, nella misura in cui i relativi membri trovino un nuovo equilibrio, anche se iniquo ${ }^{26}$.

${ }^{21}$ Ciu., V, 1. "Lo Stato è uno strumento di virtù provvidenzialmente contrapposto dalla natura ad una pur presente legge di scadimento e di corruzione morale" (A. VECCHI, Introduzione al De Civitate Dei, Edizioni Paoline, Modena, 1957, p. 120; sul carattere provvidenziale dello Stato, cfr. anche p. 102 s.). Infatti, “[...] col De Civitate Dei, si definisce sia la bontà formale dello Stato che l'irrazionale punto che ne contrassegna l'origine empirica" (A. VECCHI, Introduzione al De Civitate Dei, cit., p. 111).

22 Ciu., IV, 33 (ove si ripete il concetto: "Et ideo regna terrena et bonis ab illo dantur et malis").

23 Origene, infatti, avrebbe una concezione tendenzialmente negativa delle diversità nazionali, riconducendole alle divisioni demoniache (cfr. J. RATZINGER, Die Einheit der Nationen, cit., 2.I, pp. 47-61), anche se va riconosciuto che "[c]iò che egli combatte, è manifestamente solo la subordinazione di quanto è sacro e santo all'elemento politico e nazionale; quando l'assoluta libertà e priorità di esso è sufficientemente chiarita, anche le specificità etniche possono ritornare ad apparire al loro posto e nel loro ordine" (J. RATZINGER, Die Einheit der Nationen, cit., 2.II.2, p. 71).

24 Per ulteriori riflessioni sul punto, cfr. infra, par. 6.

${ }^{25}$ Cfr. ciu., IV, 4.

26 Rosmini ricorda: "La differenza fra lo stato de' selvaggi e lo stato de' cittadini 
Agostino conclude il capitolo esemplificando quanto appena detto con la vicenda del pirata catturato da Alessandro Magno. Il primo, interrogato dal secondo sul perché abbia turbato la pace del mare, risponde che la ragione è la stessa per cui il Macedone ha recato molestia al mondo intero. L'unica differenza tra i due, allora, non risiede nella qualità delle imprese, bensì nella quantità delle stesse, nel senso che il pirata è considerato un predatore perché si serve di una piccola nave, mentre il condottiero è considerato un imperatore perché si serve di una grande flotta. Anche qui, implicitamente, se manca la giustizia, in nulla differiscono le due condotte: cambiano soltanto i numeri dei subordinati e dei mezzi a disposizione; forse, anche il pirata avrebbe ottenuto la stessa fortuna del Macedone, se avesse avuto le medesime risorse.

Il libro IV, dopo aver svolto ulteriori considerazioni sulla storia romana e sulle vicende di altri imperi - a conferma che non si tratta soltanto di un'analisi limitata all'Urbe, ma pretende di essere universale ${ }^{27}$ , prosegue la trattazione aggredendo il pantheon politeista di Roma: l'argomentazione è spesso ironica ${ }^{28}$, ma sempre mantiene la lucidità di analisi e persegue lo scopo parallelo dell'esaltazione del vero Dio's; ed è proprio con un riferimento al monoteismo degli ebrei che si conclude il libro de quo ${ }^{30}$.

pervenuti a quest'ultima corruzione si è quasi solamente, che la corruzione de' selvaggi precede l'esistenza della società, mentre la corruzione de' cittadini sussegue all'esistenza della società, onde la società sta in piede quanto alle sue forme esteriori per qualche tempo in presenza della corruzione de' suoi membri" (A. ROSMINI, Filosofia della politica, a cura di S. COTTA, Rusconi, Milano, 1985, III.3, p. 325).

${ }^{27}$ Cfr. ciu., IV, 5 s.

${ }^{28}$ Come quando, ragionando sull'asserita maggior giustizia delle ragioni dei romani, rispetto ai nemici, si domanda perché non sia stata adorata anche l'iniquitas degli avversari, come divinità benevola per le sorti dei Quiriti: cfr. ciu., IV, 15. Oppure come quando, ricordando che i romani credevano che il dio Bronzino avesse generato il dio Argentino (perché la moneta di argento era entrata in circolazione dopo di quella di bronzo), si interroga sul perché il dio Argentino non abbia generato, a sua volta, il dio Aurino (visto che la moneta d'oro era entrata in circolazione dopo di quella di argento): cfr. ciu., IV, 21.

${ }^{29} \mathrm{Si}$ consideri la lunga riflessione sulla dea Felicitas (cfr. ciu., IV, 23-25); Agostino si domanda perché essa non sia stata subito adorata come unica divinità: "Quis enim optat aliquid propter aliud quam ut felix fiat?" (ciu., IV, 23). In tal modo, si sarebbe giunti, per l'Ipponense, a riconoscere l'esistenza del vero Dio (cfr. ciu., IV, 25 e 33).

${ }^{30}$ Cfr. ciu., IV, 34. 


\section{4 - Lo svolgimento logico della tesi agostiniana sul rapporto tra Stato e giustizia}

Sarebbe scorretto, però, restringere la trattazione del rapporto tra potere e giustizia al solo libro IV del DcD: Agostino, infatti, si occupa del tema in vari altri passi e attua un vero e proprio sviluppo del suo pensiero, che può essere compreso soltanto seguendo l'Autore nello svolgersi dell'Opera.

Così, già nel II libro, si trova il primo riferimento rilevante; per la precisione il Vescovo condivide il ragionamento di Cicerone ${ }^{31}$, il quale, a sua volta, fa parlare Scipione l'Africano:

"[...] quae harmonia a musicis dicitur in cantu, eam esse in ciuitate concordiam, artissimum atque optimum omni in re publica uinculum incolumitatis, eamque sine iustitia nullo pacto esse posse $[\ldots]^{\prime \prime 32}$. Quindi, "[...] non modo falsum esse illud, sine iniuria non posse, sed hoc uerissimum esse, sine summa iustitia rem publicam regi non posse" ${ }^{\prime \prime 3}$.

Ora, non essendo la res publica altro che res populi34, siccome "[...] nec ipse

${ }^{31}$ In generale, sul rapporto tra questi due scrittori, cfr., e pluribus: G.J.P. O'DALY, Ciuitate dei (De - ), cit., nr. 8.a), p. 999; L. ALICI, Appendici, in AURELIO AGOSTINO, La città di Dio, cit., nr. 5; E. VALGIGLIO, Sant'Agostino e Cicerone, in AA. VV., Fede e sapere nella conversione di Agostino, Università di Genova - Facoltà di Lettere - Dipartimento di Archeologia, Filologia classica e loro traduzioni, Genova, 1986, pp. 43-70. Non sempre, però, Agostino sembra citare correttamente Cicerone (cfr. É. GILSON, Les métamorphoses de la cité de Dieu, cit., II, p. 80). Più in generale, per un'analisi dei riferimenti filosofici presenti nell'Opera, cfr. R. RUSSELL, Introduzione. Filosofia, in SANT'AGOSTINO, La Città di Dio, cit., II.2, pp. CIV-CXII.

32 Ciu., II, 21.

${ }^{33}$ Ciu., II, 21.

${ }^{34}$ Cfr. ciu., II, 21. Presso i Romani, res publica connotava in senso normativo la comunità cui era riferito tale espressione, ma "non pas comme entité institutionnelle transpersonnelle, mais comme populus, peuple, c'est-à-dire, comme l'ensemble des citoyens" (W. MAGER, Res publica chez les juristes, théologiens et philosophes à la fin $d u$ Moyen Âge: sur l'élaboration d'une notion-clé de la théorie politique moderne, in AA. VV., Théologie et droit dans la science politique de l'État moderne. Actes de la table ronde de Rome, 12-14 novembre 1987, École Française de Rome, Rome, 1991, p. 230). Quindi, Agostino come Cicerone - segue la concezione tradizionale di res publica (cfr. W. MAGER, Res publica chez les juristes, cit., p. 230 s.), mentre, in epoca medievale, tale concetto assume significati diversi (cfr. W. MAGER, Res publica chez les juristes, cit., pp. 229-239). Andrebbe, però, riconosciuto che, almeno nel De libero arbitrio libri tres, il Vescovo sembra usare la categoria di res publica quale semplice termine contraddittorio di res privata (cfr. 
populus iam populus esset, si esset iniustus, quoniam non esset multitudo iuris consensu et utilitatis communione sociata, sicut populus fuerat definitus"35, deriva, inevitabilmente, che non si possa parlare di res publica, in mancanza di giustizia. Si badi che l'Autore si attiene a una visione rigorosa dello ius, del diritto, nel senso che esclude che quest'ultimo possa sussistere in assenza della giustizia. Detto altrimenti, uno ius sine iustitia non è possibile, in quanto non può aversi uno ius iniustum ${ }^{36}$.

Agostino, però, non pare soddisfatto dall'argomentazione riportata, per quanto essa sia razionale e autorevole. Infatti, egli, mentre riassume quanto acquisito e rinvia a una futura trattazione specifica del tema de $q u o^{37}$, anticipa già il criterio cardine che sarà consacrato, appunto, più oltre nel libro XIX: "uera autem iustitia non est nisi in ea re publica, cuius

lib. arb., I, VI, 14, 45 e 46), mentre, per indicare l'aggregazione politica, pare ricorrere all'espressione civitas (cfr. lib. arb., I, VI, 14, 44 e 47).

35 Ciu., II, 21.

36 Si noti che Agostino riconosce l'esistenza della categoria della legge umana ("Nam ex hominibus una lege sociatis populus constat; quae lex, ut dictum est, temporalis est" [lib. arb., I, VII, 16, 52]), che può e deve mutare ("Appellemus ergo istam legem, si placet, temporalem, quae quamquam iusta sit, commutari tamen per tempora iuste potest" [lib. arb., I, VI, 14, 48]); tuttavia, detta lex temporalis va ricondotta alla lex aeterna ("Simul etiam te uidere arbitror in illa temporali nihil esse iustum atque legitimum quod non ex hac aeterna sibi homines deriuauerint" [lib. arb., I, VI, 15, 50]). A ogni modo, non pare questa la sede per la disamina della questione se iussum quia iustum o iustum quia iussum, ma va riconosciuto che una dimensione giuridica - per quanto si possa usare il riferimento al diritto soltanto in modo improprio - sembra possibile, anzi risulta inevitabile nelle articolazioni sociali: "Se gli uomini fossero veramente cives, la civitas starebbe insieme anche senza il diritto. La necessità del diritto è soltanto la deficienza di civiltà; ancora una volta balena il significato puro di necessitas, da nec esse. Qui si imposta la distinzione tra la civitas mundi e la civitas Dei. La civitas mundi, lo Stato, è tenuta insieme veramente dal diritto. Pertanto è legata; il diritto non è che un legame. Nello Stato gli uomini sono legati come le verghe in un fascio; se non fossero legati, il fascio si sfascerebbe. Ciò che li lega, al fondo, è la paura: paura del castigo, se non ubbidiscono. Gli elementi del comando giuridico sono due: precetto e sanzione. Se non ci fosse la sanzione, il precetto, anziché un comando, sarebbe un consiglio. Perciò la civitas mundi è tenuta insieme $a b$ extra; ciò è tanto vero che quando il diritto cede, in tempi di rivoluzione, la civitas si disgrega e occorre tornarla a legare. La civitas Dei, il Corpus mysticum, la Chiesa, è tenuta insieme, anziché dal diritto, dall'amore: ab intra, anziché ab extra" (F. CARNELUTTI, "Sono stato carcerato» (Dall'uomo a Dio), in IDEM, I dialoghi del Vangelo e la civiltà. Colloqui di Francesco Carnelutti, Sansoni, Firenze, 1956, p. 60 s.).

37 "Sed alias, si Deus uoluerit, hoc uidebimus. Enitar enim suo loco, ut ostendam secundum definitiones ipsius Ciceronis, quibus quid sit res publica et quid sit populus loquente Scipione breuiter posuit [...], numquam illam fuisse rem publicam, quia numquam in ea fuerit uera iustitia" (ciu., II, 21). 
conditor rectorque Christus est, si et ipsam rem publicam placet dicere, quoniam eam rem populi esse negare non possumus" 38 . Già qui, insomma, è chiaro l'intero impianto di ragionamento, riassumibile come segue: ogni Stato presuppone un popolo, ogni popolo presuppone la giustizia, la giustizia presuppone Cristo; se manca Cristo, non vi può essere la giustizia, quindi non vi può essere popolo e, conseguentemente, non vi può essere Stato.

Le argomentazioni svolte da Agostino nel libro XIX, a ben guardare, non sono altro che una ripresa di quanto già acquisito nel libro II. Infatti, egli, in modo disteso, riflette sulla giustizia in riferimento allo Stato e al popolo, ribadendo che la prima è inderogabile condizione perché sussistano gli altri due ${ }^{39}$. Se mai, a un certo punto, introduce un tema più 'religioso', ossia la necessità che il corpo sia subordinato all'anima e che quest'ultima sia in dipendenza da Dio; in caso contrario, infatti, l'uomo sarà schiavo delle passioni e, conseguentemente, lo sarà anche l'aggregazione sociale relativa, con impossibilità, ancora una volta, di

${ }^{38}$ Ciu., II, 21.

39 "Quapropter nunc est locus, ut quam potero breuiter ac dilucide expediam, quod in secundo huius operis libro me demonstraturum esse promisi, secundum definitiones, quibus apud Ciceronem utitur Scipio in libris de re publica, numquam rem publicam fuisse Romanam. Breuiter enim rem publicam definit esse rem populi. Quae definitio si uera est, numquam fuit Romana res publica, quia numquam fuit res populi, quam definitionem uoluit esse rei publicae. Populum enim esse definiuit coetum multitudinis iuris consensu et utilitatis communione sociatum. Quid autem dicat iuris consensum, disputando explicat, per hoc ostendens geri sine iustitia non posse rem publicam; ubi ergo iustitia uera non est, nec ius potest esse. Quod enim iure fit, profecto iuste fit; quod autem fit iniuste, nec iure fieri potest. Non enim iura dicenda sunt uel putanda iniqua hominum constituta, cum illud etiam ipsi ius esse dicant, quod de iustitiae fonte manauerit, falsumque esse, quod a quibusdam non recte sentientibus dici solet, id esse ius, quod ei, qui plus potest, utile est. Quocirca ubi non est uera iustitia, iuris consensu sociatus coetus hominum non potest esse et ideo nec populus iuxta illam Scipionis uel Ciceronis definitionem; et si non populus, nec res populi, sed qualiscumque multitudinis, quae populi nomine digna non est. Ac per hoc, si respublica res est populi et populus non est, qui consensu non sociatus est iuris, non est autem ius, ubi nulla iustitia est: procul dubio colligitur, ubi iustitia non est, non esse rem publicam. Iustitia porro ea uirtus est, quae sua cuique distribuit. Quae igitur iustitia est hominis, quae ipsum hominem Deo uero tollit et inmundis daemonibus subdit? Hocine est sua cuique distribuere? An qui fundum aufert eius, a quo emptus est, et tradit ei, qui nihil habet in eo iuris, iniustus est; et qui se ipsum aufert dominanti Deo, a quo factus est, et malignis seruit spiritibus, iustus est? Disputatur certe acerrime atque fortissime in eisdem ipsis de re publica libris aduersus iniustitiam pro iustitia" (ciu., XIX, 21). 
parlare di popolo e, quindi, di Stato ${ }^{40}$. L'esposizione della visione agostiniana sul tema termina con un'ultima considerazione, questa volta sintetica:

"[...] ubi ergo non est ista iustitia, profecto non est coetus hominum iuris consensu et utilitatis communione sociatus. Quod si non est, utique populus non est, si uera est haec populi definitio. Ergo nec res publica est, quia res populi non est, ubi ipse populus non est" 41 .

\section{5 - Cristo come unico criterio per la giustizia/virtù/felicità}

Ma perché un tale peso della iustitia? Anche qui non resta che seguire il ragionamento dell'Autore. Ora, malgrado si noti l'assenza di una visione sistematica della giustizia in Agostino, nel senso che manca un'opera specificamente dedicata a tale tema ${ }^{42}$, è presente nel $D c D$ una - seppur

40 "Seruiens autem Deo animus recte imperat corpori, inque ipso animo ratio Deo Domino subdita recte imperat libidini uitiisque ceteris. Quapropter ubi homo Deo non seruit, quid in eo putandum est esse iustitiae? quando quidem Deo non seruiens nullo modo potest iuste animus corpori aut humana ratio uitiis imperare. Et si in homine tali non est ulla iustitia, procul dubio nec in hominum coetu, qui ex hominibus talibus constat. Non est hic ergo iuris ille consensus, qui hominum multitudinem populum facit, cuius res dicitur esse res publica. Nam de utilitate quid dicam, cuius etiam communione sociatus coetus hominum, sicut sese habet ista definitio, populus nuncupatur? Quamuis enim, si diligenter adtendas, nec utilitas sit ulla uiuentium, qui uiuunt impie, sicut uiuit omnis, qui non seruit Deo seruitque daemonibus, tanto magis impiis, quanto magis sibi, cum sint inmundissimi spiritus, tamquam diis sacrificari uolunt" (ciu., XIX, 21).

${ }^{41}$ Сiu., XIX, 23. Quale, allora, aggregazione umana può veramente vantare la qualifica di res publica? Cotta formula, sul punto, un giudizio netto: "Ma allora, procedendo con assoluto rigore e in piena fedeltà alla sua comprensione del significato profondo della giustizia, il ragionamento è giunto a un risultato paradossale: l'unica vera res publica è la Città di Dio, che non è di questo mondo, mentre gli Stati terreni non sono affatto delle res publicae" (S. COTTA, Introduzione. Politica, in SANT'AGOSTINO, La Città di Dio, cit., II.3, p. CXLV). Quanto a Roma, Gilson osserva: «In un certo senso c'è stata una "cosa pubblica" romana dove, soprattutto all'epoca delle origini, regnava una specie di giustizia, generatrice, essa stessa, di una specie di società. Tuttavia, poiché questa giustizia non era la "vera giustizia", neanche tale società era una "vera società". Cedendo qui alle sollecitazioni della dialettica, diremo che non vi è mai stata una società romana, in quanto non essere una vera società equivale a non esserne una» (É. GILSON, Les métamorphoses de la cité de Dieu, cit., II, p. 81 s.). Icasticamente, Vecchi osserva: "[...] la legittimità storica di un primo ordinamento costituzionale è fondata su di un atto d'arbitrio" (A. VECCHI, Introduzione al De Civitate Dei, cit., p. 67).

42 "[...] negli scritti di Agostino manca una teoria sistematica della giustizia, se con questa espressione intendiamo una trattazione esposta in opere apposite [...]. Il tema della 
rapida - definizione di essa: sua cuique tribuere ${ }^{43}$. Dare a ciascuno il suo è la nozione tradizionale di giustizia e quest'ultima non pare limitabile al mondo cristiano ${ }^{44}$, ma lo scontro con il paganesimo si verifica proprio sul terreno di cosa vada riconosciuto a chi: chiaramente, se si nega che gli dei esistano o, come minimo, li si riduce a delle entità malvagie, nessun culto potrà essere loro tributato e, viceversa, solo Dio - quindi Cristo - potrà ricevere tutta l'adorazione, in forza della giustizia.

Strettamente connesso a ciò, vi è la virtù, nozione anch'essa presente nel mondo pagano ma in modo imperfetto ${ }^{45}$ e, dunque, non riconducibile, nella sua applicazione pratica, alla visione cristiana ${ }^{46}$,

giustizia attraversa trasversalmente moltissime opere agostiniane senza esaurirsi in nessuna di esse. La presenza di considerazioni sulla giustizia in scritti differenti per natura, genesi e soggetto richiede una particolare cautela nell'accostarle tra loro. Questo tuttavia non significa affatto che le idee di Agostino in merito alla giustizia siano prive di connessioni e di coerenza logica. Al contrario, a nostro giudizio esse scaturiscono dai medesimi principi e premesse fondamentali, e sono pertanto ricomponibili entro un quadro sostanzialmente unitario" (cfr. G. CATAPANO, La giustizia nella sfera pubblica, cit., nr. 1, pp. 84-86).

43 Ciu., XIX, 4, ma molto simile anche in ivi, 21. Più elaborata la definizione in mor. I, $\mathrm{XV}$, 25: "iustitia amor soli amato seruiens et propterea recte dominans [...]. Sed hunc amorem non cuiuslibet sed dei esse diximus, id est summi boni, summae sapientiae summaeque concordiae. Quare definire etiam sic licet, ut [...] iustitiam amorem deo tantum seruientem et ob hoc bene imperantem ceteris quae homini subiecta sunt". In generale, sul concetto di giustizia in Agostino, cfr., e pluribus, É. GILSON, Les métamorphoses de la cité de Dieu, cit., II, p. 80 ss.

44 Si pensi al mondo greco-romano: "La giustizia viene esaltata come valore supremo" (G. REALE, D. ANTISERI, Il pensiero occidentale dalle origini ad oggi, I, La Scuola, Brescia, 2004, 24a ed., 1.2.1, p. 6).

45 Non pare, pertanto, accettabile la seguente affermazione: "Ai suoi occhi [di Agostino, scil.] Roma diventa il simbolo della città celeste" (A. TRAPÈ, Introduzione. Teologia, cit., I.2.2, p. XXII). Infatti, anche se Trapè riconosce le riserve di Agostino nei confronti della virtù romana, comunque non spiega perché il Vescovo finisca per negare che si tratti di vera virtù, proprio in quanto non fondata sul vero bene, ossia su Dio. Se mai, l'Autore torna a considerare il tema, accusando i giansenisti di aver travisato il pensiero agostiniano che riconoscerebbe il carattere di vere virtù a quelle romane, pur risultando esse viziate dal non essere indirizzate al sommo bene (cfr. A. TRAPE, Introduzione. Teologia, cit., I.2.3, p. XXIII).

46 "Eppure il senso nuovo di moralità cristiana esige una revisione dei miti, delle grandezze, delle glorie poste in luce di prospettiva mondana, carnale: ed in tal modo miti e grandezze e glorie accennano a sfaldarsi sotto le accuse o sotto i sorrisi ironici. Ciò soprattutto rendeva furibondi contro i cristiani gli uomini di cultura pagana. Del resto, l'austerità delle concezioni morali cristiane non poteva che assumere criticamente gli stessi residui della romanità [...]" (A. VECCHI, Introduzione al De Civitate Dei, cit., p. 61). 
proprio perché la vera virtù postula che si debba essere veramente giusti, ossia che si segua il vero bene, cioè Cristo ${ }^{47}$.

Si comprende, allora, che il discorso non può mutare, volgendosi alla felicità; ma, su quest'ultima, il pensiero di Agostino è più articolato: egli, infatti, ricorda che tutti, buoni e cattivi, agiscono e vogliono in funzione della felicità ${ }^{48}$. Logica conseguenza, quindi, sarebbe pensare che la felicità accomuni tanto i giusti che gli ingiusti e ciò parrebbe avvalorato dallo stesso Ipponense, laddove parla di Dio "[...] qui dat felicitatem in regno caelorum solis piis; regnum uero terrenum et piis et impiis, sicut ei placet, cui nihil iniuste placet" 49 . In realtà, si vede come sicuramente anche i cattivi cerchino e raggiungano la letizia, ma, per essi, quest'ultima risulterebbe, al massimo, soltanto intra-mondana; a conferma di ciò si possono addurre molti passi dai quali emerge che la vera felicità è soltanto quella dei giusti, ossia di coloro che vivono in conformità al vero Dio, in quanto le ricchezze, la gloria e il potere sono ingannevoli espressioni di felicità ${ }^{5}$. Si ricordi, inoltre, che la letizia dei malvagi, comunque, è limitata alla sola vita temporalis, rimanendo essi privi della felicità nella vita aeterna ${ }^{51}$; e, per l'appunto, Agostino postula anche che la vera felicità debba essere eterna, in quanto nessuno può venire veramente appagato da ciò che è transitorio ${ }^{52}$, così come risulta irrinunciabile, per una vita felice,

47 Significativamente, la posizione cristiana è monolitica sul punto, per cui, a distanza di secoli, Rosmini asserisce: "La virtù suppone dinanzi a sé la cognizione del vero bene" (A. ROSMINI, Filosofia della politica, cit., III.16, p. 434). E sostiene ciò proprio ricollegandosi al pensiero dell'Ipponense: "Per questo sant'Agostino nega l'esistenza d'una vera virtù là dove manca la cognizione del vero Dio, in cui quella dee terminare" (A. ROSMINI, Filosofia della politica, cit., p. 435, nt. 5). Dissente da tale lettura Giorgianni, il quale dà un'interpretazione in chiave positiva della concezione della virtù presso i pagani, secondo Agostino (cfr. V. GIORGIANNI, Il concetto del diritto e dello stato in $S$. Agostino, Cedam, Padova, 1951, II.4, p. 45 s.).

48 Cfr. s., CL, III, 4 PL.

${ }^{49}$ Ciu., V , 21.

${ }^{50}$ Cfr. ciu., I, 15, IV, 3 e V, 24; ep., CLV, 3, 9 CSEL. Poi, sulla falsa felicità proveniente dal peccato, cfr. ciu., XIV, 4 e 15.

${ }^{51}$ Cfr. s., CCXCVII, V, 8 PL.

52 Merita di essere riportato per intero il ragionamento svolto dal Vescovo: "Quamquam si diligentius adtendamus, nisi beatus non uiuit ut uult, et nullus beatus nisi iustus. Sed etiam ipse iustus non uiuet ut uult, nisi eo peruenerit, ubi mori falli offendi omnino non possit eique sit certum ita semper futurum. Hoc enim natura expetit, nec plene atque perfecte beata erit nisi adepta quod expetit. Nunc uero quis hominum potest ut uult uiuere, quando ipsum uiuere non est in potestate? Uiuere enim uult, mori cogitur. Quo modo ergo uiuit ut uult, qui non uiuit quamdiu uult? Quod si mori uoluerit, quo modo potest ut uult uiuere, qui non uult uiuere? Et si ideo mori uelit, non quo nolit 
la conoscenza della verità 53 .

Riassumendo, non pare peregrino dire che, in realtà, i concetti di giustizia, virtù e felicità sono surrogabili tra loro, in quanto hanno Cristo come unico e vero termine di riferimento; anzi, tutti e tre sono sostituibili sinteticamente proprio da Cristo il quale, in quanto vero Dio, risulta la vera giustizia ${ }^{54}$, la vera virtù e la vera felicità. Il fatto che, comunque, in realtà, nella vita terrena tale vera giustizia non paia realmente praticabile per gli uomini ${ }^{55}$ - disponendo essi soltanto di una iustitia minor ${ }^{56}$ - non può essere letto come una contraddizione di quanto appena sostenuto, bensì, se mai, una conferma dell'urgenza della grazia di Cristo, tanto per la vita del privato cittadino che per la vita della società ${ }^{57}$.

uiuere, sed ut post mortem melius uiuat: nondum ergo ut uult uiuit, sed cum ad id quod uult moriendo peruenerit. Uerum ecce uiuat ut uult, quoniam sibi extorsit sibique imperauit non uelle quod non potest, atque hoc uelle quod potest (sicut ait Terentius: Quoniam non potest id fieri quod uis. Id uelis quod possis): num ideo beatus est, quia patienter miser est? Beata quippe uita si non amatur, non habetur. Porro si amatur et habetur, ceteris omnibus rebus excellentius necesse est ametur, quoniam propter hanc amandum est quidquid aliud amatur. Porro si tantum amatur, quantum amari digna est (non enim beatus est, a quo ipsa beata uita non amatur ut digna est): fieri non potest, ut eam, qui sic amat, non aeternam uelit. Tunc igitur beata erit, quando aeterna erit" (ciu., XIV, 25). Altrove, in modo più sintetico, Agostino afferma: "Quod si uirtus ad beatam uitam nos ducit, nihil omnino esse uirtutem affirmauerim nisi summum amorem dei" (mor., I, 15, 25 CSEL); "aeternam uitam esse summm bonum" (ciu., XIX, 4).

${ }^{53}$ Cfr. s., CCCVI, X, 9 PL.

54 "Est plane ille summus deus uera iustitia uel ille uerus deus summa iustitia" (ep., CXX, 19).

55 Un'eccezione di ciò pare costituita da quanto riportato in nat. et gr., LX, 70 CSEL, ove sembra che Agostino ammetta la possibilità, per l'uomo, di una giustizia perfetta.

${ }^{56}$ Cfr. l'elaborata riflessione in spir. et litt., XXXVI, 65 CSEL. Osserva Fortin: "Soltanto nella città di Dio, la cui vita consiste nella totale acquiescenza alla rivelazione divina, si trova la vera giustizia. Poiché il suo modello è posto in cielo e la sua condizione perfetta si raggiunge soltanto nell'altra vita, la città di Dio talora è chiamata la città celeste; tuttavia, per quanto gli esseri umani, mediante l'adesione a Cristo, hanno ora la possibilità di condurre una vita virtuosa, essa esiste già qui in terra. Per questa ragione essa non va confusa con la città ideale di Platone, che non esiste in nessun altro luogo se non nel pensiero e nelle parole" (E.L. FORTIN, Civitate Dei, De, cit., p. 413). Comunque, occorre riconoscere che "[...] in una certa azione politica o sociale entra non solo in figura ma in modo precisamente reale una percentuale, senza dubbio minima e in ogni caso impossibile per noi da precisare, di autentica giustizia, un'eco e un riflesso della Giustizia [...]" (H.-I. MARROU, Théologie de l'histoire, Cerf, Paris, 2008, 2a ed., traduzione italiana a cura di G. PASQUALE, Teologia della storia, Jaca Book, Milano, 2010, 3a ed., II.9, p. 164).

57 " [...] l'ideale agostiniano dello statista cristiano è inquadrato sullo sfondo delle sue riflessioni su Cristo, perché, dal suo punto di vista, solo Cristo, con la propria mediazione, trasmette la vera virtù all'anima, e quindi allo statista. Agostino ha così cura 
Ma, allora, una volta rispettate tutte le suddette prescrizioni, sarebbe possibile parlare di un atto virtuoso e/o giusto, sarebbe possibile parlare di una vita veramente felice? In realtà no, secondo il punto di vista umano: infatti,

"[...] ogni tentativo di discriminare, fuorché in modo puramente formale, tra le due città, è condannato al fallimento, perché è impossibile conoscere con certezza se un determinato essere umano è genuinamente virtuoso oppure no" 58 .

\section{6 - Il libro XIX come allargamento dei confini della legittimità dello Stato}

L'assetto emergente dal libro II non rappresenta la visione definitiva di Agostino: bisogna leggere assieme anche quanto contenuto nel libro XIX ${ }^{59}$, ove l'Autore fornisce una definizione più articolata e meno 'rigorista' 60 :

di smontare, nella Città di Dio e nelle sue lettere a pubblici ufficiali, ogni altra spiegazione - filosofica e religiosa - della virtù politica, sulla base dell'idea per cui l'autentica virtù va intesa esclusivamente come la virtù di Cristo operante attraverso l'anima umana. Questo principio è ciò che caratterizza la radicale originalità dell'approccio agostiniano all'etica politica" (R. DODARO, I fondamenti teologici del pensiero politico agostiniano: le virtì teologali dello statista come ponte tra le due città, in Etica E Politica/Ethics E Politics, IX [2007], 2, p. 39). Quali siano, invece, le conseguenze dell'amministrazione della giustizia 'laica' si può vedere in ciu., XIX, 6. Non si dimentichi, comunque, che Agostino struttura la sua teologia politica in contrapposizione tanto al monismo stoico (per cui il divino è inglobato totalmente nel mondo) quanto all'assoluta trascendenza platonica (per cui tra divino e umano non vi può essere contatto): egli, invece, trova la chiave di volta in un equilibrio che poggia sull'incarnazione del Figlio (cfr. J. RATZINGER, Die Einheit der Nationen, cit., 3.II, pp. 87-90). Circa il ruolo centrale dell'incarnazione, per la credibilità del cristianesimo, cfr. J. GUITTON, Attualità di Sant'Agostino, traduzione italiana a cura di M.L. GuiCCIARDI, Edizioni Paoline, Roma, 1956, pp. 50-52.

58 E.L. FORTIN, Civitate Dei, De, cit., p. 413. Si inserisce, a questo punto, il tema della predestinazione, circa il quale cfr. infra, par. 10.

59 Sulla questione della giustizia, del popolo e dello Stato, rispetto ai libri II e XIX del DcD, cfr. S. COTTA, Introduzione. Politica, cit., II.3, pp. CXLIII-CXLVII. Per riflessioni sulla concezione giuridica dello Stato in Agostino e sulle relative conseguenze, cfr. anche A. VECCHI, Introduzione al De Civitate Dei, cit., pp. 65-68. Quanto al contenuto specifico del libro XIX, non si dimentichi che Agostino "[...] is speaking less of relations between Church and State than of the degree to which Christians can and must be good citizens of the Empire" (G.J.P. O'DALY, Ciuitate dei (De - ), cit., nr. 7.e], p. 995 s.).

${ }^{60}$ Detto altrimenti, sarebbe inesatto limitare lo studio politico del $D c D$ al contenuto dei soli primi libri. Ma, parimenti, non si può nemmeno descrivere la visione agostiniana dello Stato esclusivamente in base al libro XIX (come accade in M.A. RASCHINI, $L a$ 
«Si autem populus non isto, sed alio definiatur modo, uelut si dicatur: "Populus est coetus multitudinis rationalis rerum quas diligit concordi communione sociatus", profecto, ut uideatur qualis quisque populus sit, illa sunt intuenda, quae diligit. Quaecumque tamen diligat, si coetus est multitudinis non pecorum, sed rationalium creaturarum et eorum quae diligit concordi communione sociatus est, non absurde populus nuncupatur; tanto utique melior, quanto in melioribus, tantoque deterior, quanto est in deterioribus concors. Secundum istam definitionem nostram Romanus populus populus est et res eius sine dubitatione res publica» 61 .

Il Vescovo stesso propone di considerare una diversa definizione di populus, ove manchi la iustitia come elemento costitutivo: rimane, allora, quale unico fattore aggregativo, l'accordo tra soggetti per il raggiungimento di un qualsivoglia scopo comune. Sparito ogni riferimento allo ius - in quanto il diritto postula la giustizia -, a determinare la configurabilità o meno di uno popolo residua soltanto la concorde volontà dei sodali: fin tanto che vi sarà un qualcosa - qualunque cosa - a tenerli uniti, vi sarà populus e, dunque, res publica62. Ciò vale per qualunque aggregazione umana, Roma compresa ${ }^{63}$. Ma Agostino non si

problematica politica nel "De civitate Dei», in AA. VV., Fede e sapere, cit., pp. 93-111. Significativo è che Raschini misuri la giustizia "[...] sul rispetto legislativo della comunione di interessi nel cui nome gli uomini si associano per costituire un popolo" [M.A. RASCHINI, La problematica politica, cit., V, p. 101; cfr. anche VIII, p. 107]).

${ }^{61}$ Ciu., XIX, 24. Altrove, Agostino dichiara, in modo più sintetico: "hoc nobis uelimus, hoc ciuitati, cuius ciues sumus; non enim aliunde beata ciuitas, aliunde homo, cum aliud ciuitas non sit quam concors hominum multitudo" (ер., CLV, 3, 9 CSEL).

62 "È politica ogni comunità che aggreghi i propri membri attorno a valori condivisi: la forza dell'aggregazione politica dipende dall'intensità con la quale i valori sono percepiti dai membri del gruppo" (F. D’AGOSTINO, Giustizia. Elementi per una teoria, San Paolo, Cinisello Balsamo, 2006, p. 43, nr. 99).

63 Il Vescovo, infatti, sembra anche relativizzare le sue precedenti critiche alla corruzione dei costumi romani: "Quid autem primis temporibus suis quidue sequentibus populus ille dilexerit et quibus moribus ad cruentissimas seditiones atque inde ad socialia atque ciuilia bella perueniens ipsam concordiam, quae salus est quodam modo populi, ruperit atque corruperit, testatur historia; de qua in praecedentibus libris multa posuimus" (ciu., XIX, 24). E si badi che la 'rivalutazione' dell'Urbe è tale per cui, logicamente, si può parlare di una res publica non solo in riferimento a quando vigeva la prisca virtus romana (cioè, durante la repubblica), bensì anche nei periodi più dissoluti. Inoltre, coerentemente con tale nuovo impianto concettuale, Agostino afferma: "Nec ideo tamen uel ipsum non esse populum uel eius rem dixerim non esse rem publicam, quamdiu manet qualiscumque rationalis multitudinis coetus, rerum quas diligit concordi communione sociatus. Quod autem de isto populo et de ista re publica dixi, hoc de Atheniensium uel quorumcumque Graecorum, hoc de Aegyptiorum, hoc de illa priore 
limita a una ricognizione di fatto, poiché, comunque, anche qui introduce un giudizio di valore, per cui quanto migliore è il fattore aggregativo, tanto migliore sarà il popolo e viceversa. Si presenta, quindi, una sorta di gerarchia delle aggregazioni umane, che recupera il riferimento al concetto di giustizia e ordina tutto - fosse anche la peggior banda di criminali secondo la maggiore/minore vicinanza rispetto a $\mathrm{Dio}^{64}$.

Pare inevitabile, a questo punto, domandarsi il perché di tale svolta concettuale, rispetto alla posizione 'maggioritaria' dell'Opera ${ }^{65}$. Accanto a chi tende a svalutare l'innovazione contenuta nel libro XIX ${ }^{66}$, vi è chi reputa che si tratti di una conseguenza inevitabile, ossia frutto dell'esigenza di superare l'aporia nella quale si era trovato Agostino: "Come potrebbero esistere due città in una dottrina per la quale, fondandosi ogni società sulla giustizia, non può esservi che una città di Cristo fondata sulla giustizia di Cristo?"67. Quindi, secondo questa posizione, si potrebbe dire che la seconda definizione di Stato sia una soluzione contingente, un cedimento della teoria alla pratica. Ma vi è chi dissente da ciò, partendo dal dato dell'inevitabilità della dimensione sociale dell'uomo, insita nella natura di quest'ultimo ${ }^{68}$; dunque, per siffatta visione, il capitolo 24 del libro XIX non sarebbe un ripiego:

Babylone Assyriorum, quando in rebus publicis suis imperia uel parua uel magna tenuerunt, et de alia quacumque aliarum gentium intellegar dixisse atque sensisse" (ciu., XIX, 24).

64 Dal contenuto del libro XIX, in altre parole, emergerebbe che "[...] the state's concerns have a relative value to the degree to which $<$ pax $>$ or $<$ ordo $>$ is realized in it [...], even if it is <pax Babylonis $>$ that is realized [...]. But A[gostino] offers no programme for the Christianization of political institutions" (G.J.P. O'DALY, Ciuitate dei (De - ), cit., nr. 7.e], p. 996).

65 Sulle contrapposte interpretazioni che privilegiano la prima definizione di res publica, piuttosto che la seconda, cfr. M.T. CLARK, Augustine on justice, in Revue d'Études Augustiniennes, 9 (1963), p. 92, e la bibliografia ivi indicata.

66 Barr, infatti, ritiene che "only the necessity of purely human law is dropped, and why not?" (R.R. BARR, The Two Cities in Saint Augustine, in Laval théologique et philosophique, 18 [1962], p. 214); tale Autore si richiama a ciu., I, praef. per affermare: "The divine law, of course, remains" (R.R. BARR, The Two Cities in Saint Augustine, cit., p. 214, nt. 2). Ma, in detto passo, Agostino non sostiene la vincolatività del diritto divino nella definizione di populus e/o res publica. Conseguentemente, anche la seguente affermazione pare infondata: "A city can be unjust, but not a commonwealth" (R.R. BARR, The Two Cities in Saint Augustine, cit., p. 214, nt. 1).

67 É. GILSON, Les métamorphoses de la cité de Dieu, cit., II, p. 83.

68 Cfr. S. COTTA, Introduzione. Politica, cit., II.2, p. CXLI. Ciò malgrado la natura viziata dell'uomo: "Nihil enim est quam hoc genus tam discordiosum uitio, tam sociale natura" (сіи. XII, 28). 
semplicemente, perché ci sia un popolo,

“[...] è invece necessario e sufficiente l'avere un amore in comune. E tuttavia ciò non basta a renderlo un popolo giusto [...]. Pertanto S. Agostino può concludere che i Romani, come gli Assiri o i Greci ecc., hanno costituito veramente dei popoli (res publicae, regna) nel senso politico della parola, pur avendo ignorato Dio e quindi la vera giustizia"69.

In tale prospettiva, dunque, si propende per una lettura sistematica del pensiero dell'Autore e tale pare essere la posizione preferibile: non vi sarebbe, in altre parole, alcuna auto-sconfessione di Agostino - stante anche il fatto che, in realtà, già nel libro IV si era prospettata una concezione 'ampia' di Stato ${ }^{70}$-, quanto, piuttosto, una capacità di 'spersonalizzazione', una capacità di saper andare oltre il proprio punto di vista, per cercare di spiegare i fenomeni che si palesano. E certamente non pare negabile il fatto che, anche in assenza di giustizia, le aggregazioni umane vivono e, anzi, prosperano.

Riassumendo, emerge un impianto concettuale tale per cui Agostino, senza una vera contraddizione, affina il suo ragionamento nel passare dal libro II al libro XIX; in quest'ultimo risulta ammettere una definizione alternativa e neutra di populus, a partire dalla quale finisce per riconoscere e legittimare come Stato qualsiasi aggregazione umana che abbia la concordia nel perseguire qualsiasi cosa ami. Insomma, l'Ipponense, scrittore cristiano in un'epoca in cui lo Stato era cristiano, fornisce una prima ed efficace teorizzazione per l'esistenza dello Stato non solo laico - nel senso di non dipendente da alcun amor di matrice religiosa, nemmeno cristiana ${ }^{71}$-, bensì anche totalmente indifferente quanto alle finalità72. Certo gli è che, in tal modo, lo Stato vive in una situazione

${ }^{69}$ S. COTTA, Introduzione. Politica, cit., II.3, p. CXLVI.

70 Cfr. supra, par. 3. A ben guardare, anzi, le tracce in tal senso si possono trovare ancora prima nell'Opera: "Secundum probabiliores autem definitiones pro suo modo quodam res publica fuit, et melius ab antiquioribus Romanis quam a posterioribus administrata est" (ciu., II, 21). Addirittura, già nel De libero arbitrio libri tres - quindi, nel 388 (cfr. G. CATAPANO, Agostino, cit., pp. 47 e 281) -, Agostino teorizza una concezione ampia di populus: "Nam ex hominibus una lege sociatis populus constat" (lib. arb., I, VII, $16,52)$.

71 "Affermando questo, Agostino ammette implicitamente che lo Stato, per esistere, non ha bisogno della religione cristiana" (G. CATAPANO, La giustizia nella sfera pubblica, cit., nr. 2, p. 89).

$72 \mathrm{Su}$ questo aspetto si rinvia alle riflessioni infra, par. 11, con l'analisi dell'ultimo periodo di ciu., XIX, 24 e delle relative implicazioni politiche. 
precaria, dettata dalla costante provvisorietà degli equilibri, in quanto

“[...] per ogni società è importante superare il sospetto sul diritto e i suoi ordinamenti, poiché solo così si può bandire l'arbitrio e vivere la libertà in quanto bene condiviso. Il sospetto nei confronti del diritto, la rivolta contro di esso sorgeranno sempre quando il diritto stesso non apparirà più come espressione di una giustizia che sia al servizio di tutti, ma come il prodotto di un arbitrio, di una pretesa di essere nel diritto solo perché si detiene il potere su di esso"73.

In conclusione, si possono ravvisare tre livelli nei rapporti tra religione e autorità politica.

1) Il primo è quello in cui il potere pubblico professa la dottrina cristiana (ortodossa): si tratta della più completa realizzazione dello Stato, soddisfacente i requisiti tanto del libro II che del libro XIX del $D c D^{74}$.

2) Il secondo livello è quello in cui il potere politico non professa la dottrina cristiana (in quanto il legislatore è eterodosso o, financo, infedele): si tratta di una realizzazione sui generis dello Stato, nel senso che, pur non soddisfacendo i requisiti del libro II, ha pur sempre i requisiti postulati dal libro XIX del $D c D$. Il fedele, malgrado sappia che tale res publica non è veramente tale secondo l'impostazione confessionista, deve comunque obbedire ai relativi ordini, nella misura in cui codesti non ledano le prerogative della vera religione ${ }^{75}$. Ecco perché non si può attribuire ad Agostino alcuna chiusura preconcetta nei confronti della Roma pagana ${ }^{76}$. Insomma, per quanto l'autorità civile sia soggetta a

73 J. RATZINGER, Ciò che tiene unito il mondo, in IDEM, J. HABERMAS, Vorpolitische moralische Grundlagen eines freiheitlichen Staates, Katholische Akademie in Bayern, 2004, traduzione italiana di G. COLOMBI, O. BRINO, Etica, religione e Stato liberale, Morcelliana, Brescia, 2005, p. 43.

74 Che, poi, tale livello sia concretamente realizzabile, cioè che possa effettivamente darsi uno Stato giusto, id est uno stato totalmente cristiano, è altra cosa; in questa sede ci si limita a ragionare su quanto astrattamente possibile, in base alle occorrenze agostiniane.

75 Detto altrimenti, salua pietate ac religione, lo Stato va rispettato, anzi vanno rispettate tutte le differenze che sussistono tra singoli Stati (cfr. ciu., XIX, 17).

76 Sarebbe profondamente inesatto ritenere che Agostino misconosca i meriti dell'istituzione politica romana e, anzi, sembra che egli finisca per parlare di una sorta di giustizia presente in essa. Pare, infatti, significativo quanto si dice in ciu., V, 19: "[...] Romanos secundum quandam formam terrenae ciuitatis bonos [...]". Ivi, infatti, sembra emergere un apprezzamento per i Quiriti, relativamente agli standard della CS. Si noti, poi, che la genesi della città di Roma presenta dei paralleli con le vicende della CD, specialmente per quanto riguarda la remissione delle colpe. "[...] remissio peccatorum, quae ciues ad aeternam colligit patriam, habet aliquid, cui per umbram quandam simile fuit asylum illud Romuleum, quo multitudinem, qua illa ciuitas conderetur, quorumlibet 
pesanti condizionamenti in senso negativo, resta il fatto che alla politica viene riservata una grande importanza ${ }^{77}$.

3) Il terzo livello è quello in cui il potere politico non soltanto non professa la dottrina cristiana, bensì vi si oppone, calpestando le prerogative della vera religione: si tratta di un'autorità che rimane certamente uno Stato secondo l'accezione laica del libro XIX del DcD, ma che non vincola le coscienze dei fedeli, i quali sono chiamati a resistere alle relative prevaricazioni.

Laicamente parlando, comunque, per Agostino i primi due livelli sono perfettamente sovrapponibili: il combinato disposto dei libri II e XIX, infatti, dimostra come per l'Ipponense non si possa pretendere che ogni articolazione politica professi la vera religione, affinché sia definibile come 'Stato'; al Vescovo non interessa la speculazione della scienza politica, bensì la condotta dei singoli uomini ${ }^{78}$. Nella misura in cui l'autorità pubblica - qualsiasi autorità pubblica - non conculca le prerogative dei cristiani, essa è lecita e va rispettata da questi ultimi.

Non pare, pertanto, inesatto affermare che, ai fini dei rapporti tra Stato e Chiesa, risulta irrilevante la divisione tra le due civitates: anzi, sembra quasi che la dimensione religiosa venga posta in secondo piano

delictorum congregauit inpunitas" (ciu., V, 17).

77 Significativamente, Agostino riporta il fatto che Pitagora insegnava ai suoi uditori la dottrina dell'arte politica solo alla conclusione del percorso di iniziazione (cfr. ord., II, 20, 54). In riferimento, poi, al mondo cattolico, "[i]l potere, in quanto potenza, è una determinazione dell'essere e perciò essenzialmente Bene" (R. ESPOSITO, Nove pensieri sulla politica, il Mulino, Bologna, 1993, I. Politica, nr. 2, p. 24). Ciò non toglie che vi sia una sorta di antinomia presente sin da Paolo, per cui, da un lato, ogni potenza viene da Dio e, dall'altro, il potere ha un'accezione negativa (cfr. R. ESPOSITO, Nove pensieri sulla politica, cit., nr. 3, p. 27). Tuttavia, con Agostino si assiste a una virata più critica: "Anche per lui, infatti, lo Stato non è malvagio in sé; e anche per lui di esso non si può fare a meno per il freno che costituisce nei confronti di una società tendenzialmente anarchica. Ma è proprio la necessità sociale dell'ordo statuale a circoscriverne l'azione alla sfera tecnica, dell'uti inibendogli qualsiasi proiezione in quella, autentica, del frui. Che la sua istituzione abbia costituito un filtro di controllo rispetto all'intensità del conflitto naturale non toglie intanto che questo sia solo temporaneamente sedato e non già definitivamente estirpato; ma soprattutto che lo Stato stesso lo porti dentro di sé come retaggio civile di una violenza originaria - l'assassinio intrapolitico di Romolo che ripete mimeticamente quello, extrapolitico, di Caino - e solo per questo sia capace di deviarlo verso l'esterno" (R. ESPOSITO, Nove pensieri sulla politica, cit., nr. 3, p. 28; cfr. anche p. 29). Insomma, si può affermare che la dimensione politica sia profondamente ambigua, in Agostino, in quanto connotata dal peccato originale (cfr. S. COTTA, Introduzione. Politica, II.2, cit., pp. CXL-CXLIII).

${ }^{78}$ Cfr. M.A. RASCHINI, La problematica politica, cit., VIII, p. 107. 
(ossia relegata nella sfera individuale), ritornando alla ribalta solo nel caso del summenzionato terzo livello, ossia qualora lo Stato conculchi le prerogative della vera fede; solo in tale circostanza, infatti, riemerge la dimensione malvagia dell'autorità politica rispetto alla bontà della CD. Resta il fatto, comunque, che, persino in siffatta circostanza, la stigmatizzazione del potere civile non viene formulata perché quest'ultimo non professa la vera religione, bensì perché la opprime ${ }^{79}$. Detto altrimenti, Agostino si presenta come un pensatore capace di analisi laica: in lui, da un lato, non vi è dubbio che solo il cristianesimo ortodosso consenta di poter essere ascritti alla $\mathrm{CD}^{80}$, dall'altro, risulta altrettanto indubbio che, ai fini della convivenza civile, basta che il cristianesimo ortodosso non venga leso nelle sue prerogative.

\section{7 - Le due civitates 81}

La nozione di civitas è identificabile con quella di societas ${ }^{82}$ ed è lo stesso

79 Ecco perché pare eccessivo il seguente giudizio: «La lacerazione dell'individuo tra un'interiorità dichiarata non politica e una vita politica delegittimata si istituzionalizza. La doppia conciliazione dell'individuo con la comunità e della comunità con l'individuo passa sotto la superiore giurisdizione spirituale dell'ordo impersonato dalla Chiesa, che insinua negli animi un sentimento (variabile nella sua intensità) di intima disaffezione nei confronti dello stato. Il legame religioso pretende di stabilire un ordine più soddisfacente e più solido di quello politico, in quanto congiunge e rinsalda di nuovo, mediante la "colla" dell'amore, l'auctoritas e la veritas che si erano separate, garantendo certezze più solide e indicando prospettive di senso e di salvezza a uomini particolarmente tormentati da angosce e speranze specifiche e indeterminate» (R. BODEI, Ordo amoris, cit., cap. V, Nel mondo, p. 202 s.).

80 Sul valore salvifico, proprio non solo del cristianesimo, cfr. infra, par. 9, nt. 145.

81 Sulle due città, cfr., e pluribus, A. VECCHI, Introduzione al De Civitate Dei, cit., pp. 36-40. Si tratta di una soluzione ricorrente presso Agostino (cfr. en. Ps., LXI, 6; CXXXVI, 1), non riconducibile a una derivazione manichea (cfr. A. TRAPÈ, Introduzione. Teologia, cit., I.3.1, pp. XXV s.).

82 Cfr. cat. rud., XIX, 31. Anzi, in almeno un passo, Agostino sembra ritenere esemplificativo il secondo concetto rispetto al primo: "[...] quas etiam mystice appellamus ciuitates duas, hoc est duas societates hominum [...]" (ciu., XV, 1). Dunque, non paiono esserci dubbi sul fatto che quando si parla di CD e di CS non si deve subito pensare a delle entità materiali, nel senso di città di edifici, bensì a dei raggruppamenti di individui. Si può trovare, comunque, anche l'uso di urbs, proprio in riferimento alla CD e alla CS identificate con Gerusalemme e con Babilonia -, ma ciò soltanto una volta che siano stati eretti gli edifici della rispettiva civitas preesistente (cfr. en. Ps., LXIV, 2). In generale, sul concetto di materia nell'Ipponense, cfr. E. MORO, Il concetto di materia in Agostino, Aracne, Canterano, 2017. 
Agostino a fornire la spiegazione della scelta, riconducendola a un'opzione biblica ${ }^{83}$, anche se non si possono dimenticare i condizionamenti 'ambientali'84. Il concetto di civitas, poi, non è da intendersi esclusivamente in senso mistico ${ }^{85}$, bensì risulta 'neutro', ossia spendibile anche in relazione alle realtà concrete, alle articolazioni terrene: ecco, dunque, le definizioni di "hominum multitudo aliquo societatis uinculo conligata" $86 \mathrm{o}$, sinteticamente, di "concors hominum multitudo" 87 . La scelta minimale, in tal senso, pare coerente con l'evoluzione del concetto di Stato. Se, infatti, civitas fosse definita presupponendo anche il concetto di giustizia, si avrebbe, come conseguenza, che solo la CD sarebbe vera città e non, certamente, la $\mathrm{CS}^{88}$; invece, Agostino deve garantire una qualche base comune tra le due civitates, quindi rinvia alla

83 "[...] quas ciuitates duas secundum scripturas nostras merito appellare possemus" (ciu., XIV , 1). Per le relative occorrenze in ambito biblico, cfr. C. LEPELLEY, Ciuis, ciuitas, in C. MAYER et ALII (eds.), Augustinus-Lexikon, cit., nr. 1, p. 942 s.

84 Trattasi, infatti, di un termine pregnante per la cultura dell'epoca (cfr. C. LEPELLEY, Ciuis, ciuitas, cit., nr. 2, pp. 943-947). In particolare, si ricordi che un uomo contemporaneo di Agostino aveva una duplice cittadinanza: quella romana (dopo l'editto di Caracalla del 212 d.C.) e quella della città di appartenenza (cfr. C. LEPELLEY, Ciuis, ciuitas, cit., p. 946). La nozione di civitas, poi, rimanda a un'idea di perfezione, per la cultura romana (cfr. C. LEPELLEY, Ciuis, ciuitas, cit., p. 947). Secondo O'Daly, la scelta di civitas dipende semplicemente dalla traduzione latina del termine $\pi o ́ \lambda ı s$, contenuto nella traduzione dei LXX (cfr. G.J.P. O’DALY, Ciuitate dei (De - ), cit., nr. 1, p. 969, anche per le relative occorrenze). Sul termine in questione, sui suoi sinonimi e collegati, cfr. anche $\mathbf{E}$. LAMIRANDE, Ciuitas dei, in C. MAYER et ALII (eds.), Augustinus-Lexikon, cit., nr. 1, p. 958, mentre sulle fonti dell'espressione, nonché sugli utilizzi previ, cfr. E. LAMIRANDE, Ciuitas dei, cit., nr. 2, p. 958 s. Non si dimentichi, poi, che, con il Nuovo Testamento, accanto alla nozione dei due Adami, si attesta la dottrina "[...] delle due $\pi$ ó $\lambda \varepsilon 1 \zeta$ in contrasto con l'idea greco-romana dell'una e unica кобнó $\pi \mathrm{o} \lambda \iota \varsigma$, che dapprima implicò

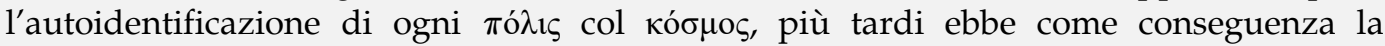
trasposizione della equiparazione $\pi$ ó $\lambda \iota \varsigma=\kappa o ́ \sigma \mu о \varsigma$ alla $\pi$ ó $\lambda \varsigma$ Roma, unica rimasta. [...] La dottrina delle due $\pi$ ó $\lambda \varepsilon 1 \varsigma$, che fin dall'Apocalisse apparteneva al patrimonio consolidato della predicazione cristiana, non è che l'applicazione della dottrina dei due Adami all'immagine di Gerusalemme [...]" (J. RATZINGER, Die Einheit der Nationen, cit., 1.II, pp. 27-29).

${ }^{85} \mathrm{Cfr}$. ciu., $\mathrm{XV}, 1$. Inoltre, emerge che anche i vari nomi attribuiti a tali due città sono da intendersi misticamente (cfr. en. Ps., LXI, 6). Lamirande ritiene più opportuno parlare di uso allegorico (e non mistico) del termine civitas, rispetto alla Bibbia (cfr. E. LAMIRANDE, Ciuitas dei, cit., nr. 6, p. 961).

${ }^{86}$ Ciu., XV, 8.

${ }^{87} \mathrm{Ciu} ., \mathrm{I}, 15$.

${ }^{88}$ Gli stessi Stati, infatti, dovrebbero attuare totalmente la giustizia di Cristo per poter essere considerati res publicae (cfr. supra, par. 4 e s., nonché par. 6, nt. 74). 
qualifica 'laica' di Stato in forza del libro XIX, così come pare logica conseguenza che l'Autore affermi: "Populus una ciuitas est" 89.

Concentrandosi, ora, sulla sola dimensione mistica, si deve riconoscere che le civitates sono sì più di una, ma soltanto due, in quanto non esistono quattro società di esseri intelligenti, due di angeli e due di uomini, bensì soltanto due popoli ${ }^{90}$, nei quali l'insieme degli esseri razionali (angeli e uomini, anche se non significa che le due categorie siano perfettamente sovrapponibili ${ }^{91}$ ) è diviso, rispettivamente tra buoni e cattivi ${ }^{92}$. Dalle occorrenze testuali nel $D c D$ è questo l'assetto che emerge e, dunque, non pare sostenibile nemmeno la tesi dell'esistenza di un terzo genere intermedio tra le due città, di una terza civitas, che favorisca la loro coabitazione ${ }^{93}$. Per Agostino, in altre parole, i populi sono soltanto due e ogni eventuale diversa razionalizzazione sicuramente sembra lecita, in

89 Ord., II, 18, 48. Con ciò, portando Agostino alle estreme conseguenze, si può concludere affermando la seguente identità: civitas $=$ societas $=$ populus $=$ res publica .

90 Cfr. ciu., XII, 1.

91 Come risulta, ad esempio, qui: "Ierusalem in Babylonia captiua tenebatur non tota: ciues enim eius et angeli sunt" (en. Ps., CXXXVI, 1).

$92 \mathrm{Si}$ badi che lo stesso vale anche per la divisione dell'unico genere umano: "[...] non tamen amplius quam duo quaedam genera humanae societatis existerent [...]" (ciu., XIV, 1; cfr. anche vera rel., XXVII, 50). Egualmente, esistono soltanto due tipi di pace, uno per ciascuna civitas (cfr. ciu., XIV, 1); si noti, pertanto, che la pace terrena (cfr. ciu., XIX, 17) è identificata come pax Babylonis (cfr. ciu., XIX, 26).

93 Cfr. E. LAMIRANDE, Ciuitas dei, cit., nr. 9, p. 964 s., anche per le diverse posizioni dottrinali. Interessante - seppur non adesa al dato letterale - la concezione di Marrou, il quale muove dalla seguente domanda: "La question est précise: y a-t-il place, dans la perspective augustinienne, à côté des deux notions antithétiques civitas Dei et civitas terrena (ou diaboli) pour un troisième élément, tertium quid? Son importance, son intérêt apparaissent bientôt: de la solution dépend le jugement porté, au nom de la doctrine augustinienne, sur la valeur de l'activité terrestre de l'homme, sur l'état, la société, la civilisation, la technique, la culture" (H.-I. MARROU, Civitas Dei, civitas terrena, num tertium quid?, in IDEM, Christiana tempora. Mélanges d'histoire, d'archéologie, d'épigraphie et de patristique, École Française de Rome, Rome, 1978, p. 415). Ebbene, dato che due soli sono gli amori, non ci possono che essere due sole città (cfr. H.-I. MARROU, Civitas Dei, cit., pp. 419-421). Conseguenza diretta di ciò è: "Il n'y a rien qui soit neutre [...] Je ne vois donc pas la possibilité d'admettre, dans la perspective augustinienne, l'autonomie d'une troisième cité de l'homme" (H.-I. MARROU, Civitas Dei, cit., p. 421). Ma, allora, non esiste un tertium quid? Per l'Autore sì, ma solo in una dimensione empirica: «Oui, il y a quelque chose d'autre, bien entendu d'un ordre tout différent, c'est ce que je proposais d'appeler "le donné empirique de l'histoire", ce donné mystérieux où bien et mal, cité de Dieu et cité du diable sont inextricablement mêlés. Si l'on veut un terme augustinien pour le désigner, je proposerai celui de saeculum [...]» (H.-I. MARROU, Civitas Dei, cit., p. 421). In generale, sul saeculum, cfr. H.-I. MARROU, Civitas Dei, cit., pp. 421-423. 
capo agli interpreti, ma non se ci si voglia attenere letteralmente al testo ${ }^{94}$. Pare importante, a questo punto, ricostruire brevemente lo svolgimento logico e cronologico dei rapporti tra $\mathrm{CD}$ e $\mathrm{CS}^{95}$. Come prima osservazione, si deve notare che Agostino, sin dal titolo della presente Opera $^{96}$, non parla di due città, bensì di una sola ${ }^{97}$. Ciò non pare una scelta casuale, anzi: è chiaro che, per l'Autore, non può che esserci una sola

94 Certo, va riconosciuto che, talora, Agostino stesso potrebbe aver contribuito a far propendere per la struttura ternaria. Infatti, non mancano passaggi in cui si parla della civitas terrena: potrebbe trattarsi di un'articolazione neutra, a cavallo tra la CD e la CS? In realtà no, poiché civitas terrena viene usato in contrapposizione proprio a $\mathrm{CD}$ e ciò lo si vede sin dall'inizio dell'Opera (cfr. ciu., I, praef.), oltre che nei passaggi chiave (cfr. ciu., XIV, 28): quindi l'espressione non è altro che un sinonimo di civitas diaboli, la CS. Sulla coincidenza di tali due espressioni, cfr. H.-I. MARROU, Civitas Dei, cit., p. 415. Quest'ultimo Autore, comunque, ritiene che alla CD si contrapponga non la civitas diaboli - che sarebbe termine di Ticonio, usato da Agostino solo "[...] eccezionalmente in un contesto retorico [...]" -, bensì la civitas terrena, salvo poi finire per riconoscere che, in quest'ultima, "[...] l'uomo, dimentico di Dio, diventa idolatra di se stesso" (H.-I. MARROU, Théologie de l'histoire, cit., I.11, p. 81). Tant'è che, altrove, egli afferma: «Ci si è spesso scandalizzati del significato alla fin fine peggiorativo che sotto la penna fremente di sant'Agostino riveste spesso il termine di civitas terrena. È evidente che, considerata nella sua essenza, la "città terrestre", la città temporale non è un ordine di realtà condannabile: essa è il quadro normale in cui si dispiega la condizione umana creata da Dio [...]. Ma ecco, ciò che esiste realmente non è solo la natura buona voluta dal buon Creatore. Nella storia e nella vita noi siamo alle prese con la natura vitiata, con la natura indebolita e deformata dal peccato» (H.-I. MARROU, Théologie de l'histoire, cit., II.15, p. 188 s.). Contro l'identificazione tra civitas terrena e CS si esprime Barr: "We are not raising the question whether Saint Augustine ever uses the expression "civitas terrena" for "political state" - this he surely does (e.g. XV, 2 [417); but in these few cases "civitas terrena" is not synonymous with "civitas diaboli" (as it usually is)» (R.R. BARR, The Two Cities in Saint Augustine, cit., p. 225, nt. 10). Invece, proprio il passo citato del DcD indica un'equazione tra civitas terrena e CS, nel senso che la prima non è un tertium genus, oltre alla CD. Comunque, si noti quanto puntualizzato da R.R. Barr: "there is apparently some relationship between them, as between the City of God and the Church, although more tenuous" (R.R. BARR, The Two Cities in Saint Augustine, cit., p. 226). Ai fini del presente studio, si preferisce usare CS, onde evitare ogni ambiguità con l'articolazione terrena della Chiesa. Il discorso non cambia per quanto riguarda l'espressione civitas hominum: anch'essa risulta un sinonimo di CS, in quanto contrapposta alla CD ("Natus est igitur prior Cain ex illis duobus generis humani parentibus, pertinens ad hominum ciuitatem, posterior Abel, ad ciuitatem Dei" [ciu., XV, 1]).

95 Plurimi sono i riferimenti - anche esterni al $D c D$ - all'origine delle due città: cfr. cat. rud., XIX, 31, XX, 36 e XXI, 37.

96 Lo stesso dicasi, comunque, anche dell'incipit del libro I.

97 Significativamente, inoltre, Agostino sottolinea come la CS non sia eterna, in quanto, una volta che sarà stata condannata al supplizio eterno, non sarà più una civitas (cfr. ciu., XV, 4). 
originaria civitas. Dio ha voluto soltanto la CD, la città dei giusti98; altrimenti, inevitabilmente, Dio avrebbe voluto il male, presupposto per l'esistenza di un'altra città, la CS ${ }^{99}$. Come noto, Agostino - una volta convertito al cristianesimo - ha difeso per tutta la vita la verità che il male non è una sostanza esistente $a b$ aeterno e che Dio non crea nulla di malvagio ${ }^{100}$ : quindi, è logico che, nel $D c D$, il Vescovo si mantenga fedele e coerente al proprio pensiero, evitando di ingenerare l'idea di due civitates coeterne, quali espressione di due principî altrettanto coeterni.

Dio ha creato soltanto enti buoni e questo vale anche per gli enti intelligenti, quali gli angeli e gli uomini. Tuttavia, Satana e altri angeli si sono ribellati, pervertendosi e venendo, perciò, precipitati negli inferi da Dio $^{101}$. Tale atto di disobbedienza segna la nascita della CS ${ }^{102}$. Già qui si può procedere a una prima distinzione: la $C D$ è stata fondata da Dio, mentre la CS è stata fondata da Satana ${ }^{103}$. Ora, prescindendo dalla questione se Adamo sia stato creato prima o dopo la ribellione di Lucifero, resta il fatto che, in origine, alla CS appartengono soltanto gli angeli cattivi; Adamo, quindi, non è geneticamente riconducibile alla CS, poiché, in lui, vi era la facoltà (id est la grazia) di non voler peccare e di poter

98 Denominata anche come sancta civitas (cfr. conf. XI, 2, 3).

99 Fondatore della CD è Dio stesso ("Huic conditori sanctae ciuitatis [...]" [ciu., XI, 1].). Per le varie occorrenze, cfr. E. LAMIRANDE, Ciuitas dei, cit., nr. 4, p. 960, nt. 6. Ma in Gn. litt., XI, 15 CSEL è ambigua la posizione dell'origine delle due città; infatti sembra che sia stato Dio ad averle fondate entrambe: "Hi duo amores [...] distinxerunt conditas in genere humano ciuitates duas sub admirabili et ineffabili prouidentia dei cuncta, quae creat, administrantis et ordinantis, alteram iustorum, alteram iniquorum".

100 E pluribus, già in relazione agli angeli stessi, cfr. ciu., XII, 1. Il peccato, poi, si ha "cum quisque auertitur a diuinis uereque manentibus et ad mutabilia atque incerta conuertitur" (lib. arb., I, 16, 35, 116). Più in generale, è un'inconuenientia rispetto ad altro (cfr. mor., II, 8, 11 CSEL).

101 Si noti che Agostino non si sbilancia sul numero complessivo dei membri della CD, limitandosi a prospettare la possibilità che gli uomini eletti accrescano la massa dei beati: "qui [Dio, scil.] de mortali progenie merito iusteque damnata tantum populum gratia sua colligit, ut inde suppleat et instauret partem, quae lapsa est angelorum, ac sic illa dilecta et superna ciuitas non fraudetur suorum numero ciuium, quin etiam fortassis et uberiore laetetur" (ciu., XXII, 1).

102 La diversità tra le due città (non materiali) nasce con la diversità degli angeli, nel senso di una differenza non di nature, bensì di volontà (cfr. ciu., XII, 1 e Gn. litt., XI, 15 CSEL: "Hi duo amores [...] praecesserunt in angelis, alter in bonis, alter in malis").

103 E Satana risulta esserne il regnante: "[...] ciuitates duas, unam diaboli, alteram Christi, et earum reges diabolum et Christum" (ciu., XVII, 20). 
perseverare in tale proposito ${ }^{104}$.

Lo sviluppo successivo si ha quando il Progenitore disobbedisce al comandamento del Creatore: con tale gesto, il peccato entra nel genere umano e si propaga inevitabilmente a tutte le generazioni. Non risulta importante, qui, sapere se Adamo appartenga alla CD o alla CS105, bensì notare che, con costui, la CS si 'allarga', per così dire, anche agli uomini; a causa sua, infatti, tutta l'umanità è un'unica massa di dannati, in quanto affetta dallo stigma del peccato originale. Ma non è ancora conclusa la genesi delle due civitates. Infatti, a questo punto, sono venute a esistere,

104 Giova ricordare, infatti, che la condizione ante-lapsaria avrebbe consentito all'uomo di perserverare, se l'avesse voluto. Infatti, i Progenitori sono stati abbandonati da Dio solo perché hanno previamente abbandonato Dio (la loro anima "non enim deserta est ut desereret, sed ut desereretur deseruit [...] Qua die me deserueritis per inoboedientiam, deseram uos per iustitiam" [ciu., XIII, 15]), sicché si può affermare: "persuasum est illud peccatum, sicut persuaderi talibus posset" (Gn. litt., XI, 42 CSEL). Su Adamo, che prima abbandona e poi è abbandonato, cfr. anche corrept., XI, 31 CSEL. Quindi Adamo aveva le risorse per perseverare. Osserva Catapano: "I battezzati che ricadono nel peccato e vi rimangono, invece, evidentemente avevano ottenuto una grazia come quella di Adamo, ossia la grazia di poter perseverare volendo, ma non quella di voler perseverare, che è data solo ai predestinati; non aver perseverato, comunque, è dipeso dal loro libero arbitrio (essi non hanno voluto perseverare), perciò essi meritano di essere rimproverati" (G. CATAPANO, Agostino, cit., VIII, p. 246 s.). In realtà, quella prospettata dall'Autore non pare una posizione condivisibile: infatti, come possono essere biasimati coloro che non perseverano, se Dio non li dota (o li priva) della grazia di perseverare? Come possono essere stigmatizzati coloro che sono privi (o sono stati privati) della grazia di persevere?

105 Lamirande reputa che Adamo appartenga alla CD (cfr. E. LAMIRANDE, Ciuitas dei, cit., nr. 5, p. 961). Sul punto, invece, Barr non si sbilancia e, anzi, rimane adeso al dato letterale: "Virtually, the earthly history of the cities began in Adam - in actuality, the City of God began in Abel [...], while the City of the Devil began actually in Cain [...]" (R.R. BARR, The Two Cities in Saint Augustine, cit., p. 222). Decisivo pare il seguente passo: "in hoc [primo] homine, qui primitus factus est, nondum quidem secundum euidentiam, iam tamen secundum Dei praescientiam exortas fuisse existimemus in genere humano societates tamquam ciuitates duas. Ex illo enim futuri erant homines, alii malis angelis in supplicio, alii bonis in praemio sociandi, quamuis occulto Dei iudicio, sed tamen iusto" (ciu., XII, 28). Si può notare, infatti, come Agostino specifichi due aspetti: in Adamo hanno sì origine ambedue le città, ma limitatamente al genere umano (non, quindi, quanto agli angeli); tale inizio avviene soltanto secondo la prescienza di Dio, quindi "not in actuality" (R.R. BARR, The Two Cities in Saint Augustine, p. 217). Siffatto assetto può spiegarsi con un duplice obiettivo: confermare la discendenza materiale, dal Progenitore, di tutti gli uomini, quindi astrattamente dannati per le conseguenze del peccato originale (cfr. ciu., XXI, 12: "Hinc est uniuersa generis humani massa damnata; quoniam, qui hoc primus admisit, cum ea quae in illo fuerat radicata sua stirpe punitus est"); confermare, nella medesima discendenza, anche Gesù Cristo, novello Adamo e redentore di tutti gli uomini. 
propriamente parlando, soltanto le due società intese in senso astratto: potremmo parlare di due città ancora 'dematerializzate', anche se non c'è dubbio che sia già divinamente stabilita l'appartenenza di ciascun uomo all'una piuttosto che all'altra ${ }^{106}$.

Solo con Caino e Abele la distinzione delle due città si fa visibile ${ }^{107}$ : eccettuato Adamo che sembra godere di uno status particolare, Caino è il primo uomo ascritto alla CS, mentre Abele è il primo uomo ascritto alla CD; infatti, "Caino ed Abele produssero la separazione delle due società temporali, come già gli angeli ribelli e fedeli, la separazione delle sovratemporali"108. Agostino vuole precisare due aspetti ${ }^{109}$ : in primo luogo, che Caino è stato partorito prima di Abele, ciò a confermare che ogni uomo nasce dannato, in quanto discendente di Adamo ${ }^{110}$; in secondo luogo, che Caino è stato il fondatore anche della prima città fisica111,

106 Trattasi del tema della predestinazione, per il quale si rinvia a infra, par. 10.

107 "[...] all'origine stessa della storia umana appaiono due specie di uomini: Abele e Caino" (É. GILSON, Les métamorphoses de la cité de Dieu, cit., II, p. 89).

108 V. GIORGIANNI, Il concetto del diritto, cit., IV.2, p. 116.

109 Ambedue sono enunciati in ciu., XV, 1: "Natus est igitur prior Cain ex illis duobus generis humani parentibus, pertinens ad hominum ciuitatem, posterior Abel, ad ciuitatem Dei. Sicut enim in uno homine, quod dixit apostolus, experimur, quia non primum quod spiritale est, sed quod animale, postea spiritale (unde unusquisque, quoniam ex damnata propagine exoritur, primo sit necesse est ex Adam malus atque carnalis; quod si in Christum renascendo profecerit, post erit bonus et spiritalis): sic in uniuerso genere humano, cum primum duae istae coeperunt nascendo atque moriendo procurrere ciuitates, prior est natus ciuis huius saeculi, posterius autem isto peregrinus in saeculo et pertinens ad ciuitatem Dei, gratia praedestinatus gratia electus, gratia peregrinus deorsum gratia civis sursum. Nam quantum ad ipsum adtinet, ex eadem massa oritur, quae originaliter est tota damnata; sed tamquam figulus Deus (hanc enim similitudinem non impudenter, sed prudenter introducit apostolus) ex eadem massa fecit aliud uas in honorem, aliud in contumeliam. Prius autem factum est uas in contumeliam, post uero alterum in honorem, quia et in ipso uno, sicut iam dixi, homine prius est reprobum, unde necesse est incipiamus et ubi non est necesse ut remaneamus, posterius uero probum, quo proficientes ueniamus et quo peruenientes maneamus. Proinde non quidem omnis homo malus erit bonus, nemo tamen erit bonus qui non erat malus; sed quanto quisque citius mutatur in melius, hoc in se facit nominari, quod adprehendit, celerius et posteriore cooperit uocabulum prius. Scriptum est itaque de Cain, quod condiderit ciuitatem; Abel autem tamquam peregrinus non condidit. Superna est enim sanctorum ciuitas, quamuis hic pariat ciues, in quibus peregrinatur, donec regni eius tempus adueniat, cum congregatura est omnes in suis corporibus resurgentes, quando eis promissum dabitur regnum, ubi cum suo principe rege saeculorum sine ullo temporis fine regnabunt".

110 Agostino ricorda: "[...] uniuersa massa tamquam in uitiata radice damnata est [...]" (ivi, XIV, 26). Cfr. anche ivi, XXI, 12 (il testo è citato supra, alla nt. 105).

111 Si noti come tale aspetto risulta negletto nelle opere che cercano di sminuire le 
mentre Abele non ha compiuto nulla di simile, ciò a sottolineare che il Fratricida è distante dal progetto di Dio ${ }^{112}$.

Insomma, con i due fratelli nascono le articolazioni terrene delle due città113, nel senso che, con loro, le due società si separano anche materialmente ${ }^{114}$. Attenzione, però: che tali due civitates si distinguano anche in relazione ai corpi materiali degli esseri umani non significa che esse siano distinguibili, da parte degli uomini stessi. Infatti, sino alla consumazione del tempo, le due società permangono commiste: è come se Agostino volesse prevenire qualsiasi tentazione donatista di erigere un'articolazione ecclesiale terrena riservata ai predestinati. Ciò, per l'appunto, è impossibile a realizzarsi, da parte degli uomini, proprio perché questi non possiedono la piena percezione della volontà divina ${ }^{115}$.

\section{8 - L'assetto delle due città nel saeculum}

Paradossalmente, risulta incontrovertibile proprio quello che sembra concettualmente più difficile da comprendere, ossia il rapporto tra le due società nel saeculum ${ }^{116}$; Agostino, infatti, per descrivere tale relazione usa

critiche di Agostino al dato politico: cfr., e pluribus, V. GIORGIANNI, Il concetto del diritto, cit., IV, specialmente § 6, p. 137. Invece, per Agostino, è un dato pacifico (cfr. anche ciu., $\mathrm{XV}, 5)$.

112 Cfr. E. LAMIRANDE, Ciuitas dei, cit., nr. 5, p. 961.

$113 \mathrm{Si}$ badi che, talora, Agostino fa direttamente riferimento proprio soltanto alla cronologia umana delle due città; ciò pare evidente in en. Ps., LXI, 6: " [...] una ciuitas et una ciuitas, unus populus et unus populus, rex et rex. Quid est: una ciuitas et una ciuitas? Babylonia una; Ierusalem una. Quibuslibet aliis etiam mysticis nominibus appelletur, una tamen ciuitas et una ciuitas: illa rege diabolo; ista rege Christo. [...] Illa enim in terra quasi maior est tempore; non sublimitate, non honore. Ciuitas illa prior nata; ciuitas ista posterior nata. Illa enim incoepit a Cain; haec ab Abel. Haec duo corpora sub duobus regibus agentia, ad singulas ciuitates pertinentia, aduersantur sibi usque in finem saeculi, donec fiat ex commixtione separatio [...]".

114 'Materialmente' nel senso dei corpi, però, e non di circoscrizioni urbane edificate, che verranno a esistere soltanto in seguito: "Ierusalem accepit exordium per Abel; Babylon per Cain; aedificia quippe urbium postea facta sunt" (en. Ps., LXIV, 2). Le due città, d'altronde, "[...] non sono entità empiriche, paragonabili alle città nel senso ordinario e identificabili con i loro confini geografici" (E.L. FORTIN, Civitate Dei, De, cit., p. 409).

115 Si rinvia a infra, par. 8.

116 Anzi, la storia delle due città è proprio il tempo: "Hoc enim uniuersum tempus siue saeculum, in quo cedunt morientes succeduntque nascentes, istarum duarum ciuitatum, de quibus disputamus, excursus est" (ciu., XV, 1). Sul concetto di saeculum, cfr. H.-I. 
una coppia di aggettivi: perplexae e permixtae ${ }^{117}$. A prima vista potrebbe apparire come un'endiadi, ma in realtà tali termini denotano due aspetti non perfettamente coincidenti. Così, perplexus si potrebbe tradurre con intricato, nel senso di impossibilità, per l'osservatore esterno, di discernere la CD dalla CS; permixtus, invece, si potrebbe tradurre con implicato, nel senso che le due città sembrano esse stesse presupporsi reciprocamente ${ }^{118}$. La condizione emergente da tali due aggettivi, comunque, è destinata a cessare con il giudizio universale: tutto quest'impianto concettuale, infatti, viene sempre circoscritto da Agostino in hoc saeculo119; d'altronde, per l'Autore non vi sono dubbi circa la netta differenza $a b$ origine tra le due società, differenza che è già ravvisabile sub specie aeternitatis.

Come avvenga siffatta commixtio tra le due società non può essere pienamente spiegato e il Vescovo, significativamente, in un passaggio,

MARROU, Civitas Dei, cit., pp. 421-423.

117 "Perplexae quippe sunt istae duae ciuitates in hoc saeculo inuicemque permixtae, donec ultimo iudicio dirimantur" (ciu., I, 35; cfr. anche X, 32 e XI, 1). In ciu., XVIII, 54 e XIX, 26, Agostino usa soltanto il termine permixtae. In en. Ps., LXI, 6 e Gn. litt., XI, 15 CSEL, parla di commixtione. In en. Ps., LXI, 8, commixtio è adoperato assieme a permixtae. Si badi che il diritto romano distingue tra l'istituto della confusio e quello della commixtio, riservando il secondo all'eventualità in cui, dall'unione di due cose, derivi un'entità le cui parti mantengono la loro individualità (cfr. A. BURDESE, Manuale di diritto privato romano, Utet, Torino, 1993, 4a ed., VII.12, p. 326 s.).

118 Detto altrimenti, Agostino potrebbe aver descritto il legame tra le due città in base a due punti di vista differenti. Marrou, a tal proposito, traduce così: "perché le due città in questo mondo sono intricate fra loro [come i gambi di vimini di un paniere] e profondamente confuse [come in una emulsione chimica] finché il giudizio finale non le separi" (H.-I. MARROU, Théologie de l'histoire, cit., I.17, p. 99). Altrove, l'Ipponense parla dei benefici temporali "[...] quae diuina prouidentia permixte bonis malisque concedit [...]" (ciu., V, 18). D'altronde, si riconosce la bontà della CS nella misura in cui quest'ultima si sforza di operare il minor male possibile, di modo che sarà da preferire quel potere umano che maggiormente si avvicina alla pace della CD (cfr. ciu., XV, 4); anzi, la stessa CD peregrinante sulla terra trae beneficio dalla (relativa) pace garantita dalla CS (cfr. ciu., XIX, 13 e 17), senza contare che ambedue le città condividono beni e mali del mondo, seppur con un diverso approccio (cfr. ciu., XVIII, 54). Infatti, non pare peregrino porsi la seguente questione: "Chi saprebbe misurare con precisione quale percentuale rilevante della Città di Dio, quale $100-\mathrm{x} \%$ attribuibile alla città del male era implicato in ogni caso?" (H.-I. MARROU, Théologie de l'histoire, cit., I.17, p. 102). Ecco perché, «[...] in ultima analisi, tutto ciò che possiamo fare, tutto ciò che si realizza nella storia, in qualche modo appartiene sia alla Città di Dio, sia alla "città avversa"» (H.-I. MARROU, Théologie de l'histoire, cit., II.5, p. 149).

119 Questo complemento di tempo (o espressioni simili) è sempre presente in tutte le citazioni di cui supra, nt. 117, e ne costituisce parte integrante. 
ricorre all'espressione quodam modo ${ }^{120}$ : in altre parole, ben poco si può dire della maniera in cui la CD e la CS sono tra loro frammiste ${ }^{121}$. Ma non potrebbe che essere così: ogni tentativo di razionalizzare, sul tema, presupporrebbe, in capo all'interprete, la conoscenza della praescientia di Dio e della sua volontà di predestinazione circa i singoli uomini; pretesa evidentemente risibile, in quanto implicherebbe che una creatura possa avere prescienza della prescienza del Creatore ${ }^{122}$. Non resta, allora, che attendere l'ultimo giudizio, quando la distinzione tra CD e CS sarà chiara e incontrovertibile ${ }^{123}$.

Concludendo su questo punto, sembra fondamentale un breve passaggio: "De ciuitatum duarum, quarum Dei una, saeculi huius est altera, in qua est, quantum ad hominum genus pertinet, etiam ista peregrina"124. Può sembrare una delle tante occorrenze dalle quali emerge la contrapposizione tra le due città, ma, in realtà, fornisce una visione che si potrebbe definire insiemistica. Agostino sottolinea come la città terrena inglobi, in parte, quella celeste; per la precisione, l'intersezione avviene in relazione a quella porzione della CD che riguarda il genere umano. Il testo latino pare chiaro nel riferire alla civitas huius saeculi, e non al saeculm in sé, la relazione della $\mathrm{CD}^{125}$.

${ }^{120}$ Cfr. ciu., XI, 1.

${ }^{121}$ Si noti che, sul punto, Agostino non sembra aver fatto progressi, rispetto alle riflessioni in Gn. litt., XI, 15 CSEL: "quarum etiam quadam temporali conmixtione peragitur saeculum, donec ultimo iudicio separentur". In generale, sull'imperscrutabilità dei disegni divini, cfr. H.-I. MARROU, Théologie de l'histoire, cit., I.14, p. 92 s.; I.16, p. 98; II.10, p. 169.

122 L'Ipponense mette in luce la peculiarità di Dio, il quale conosce "non ut homo, qui hominem ad praesens uidet" (ciu., XX, 7).

${ }^{123}$ Sulla condizione della CD nell'eternità, cfr. ciu., V, 16. Sui due fines delle due città dopo il giudizio universale, cfr. ench., XXIX, 111. "Due civitates si scontrano, coesistono e si confondono infatti nel saeculum come il grano e la zizzania. Nell'historia anceps, historia bifrons in cui saremo immersi sino alla fine dei tempi, solo l'ultimo giudizio le separerà, sceverando i due amori che indirizzano il proprio appetitus in campi opposti e ponendo così fine all'ambiguità della storia nella sconfitta del male e nel trionfo definitivo del bene" (R. BODEI, Ordo amoris, cit., cap. V, Nel mondo, p. 191). Ecco perché, allora, risulterebbe un tradimento della concezione agostiniana ogni tentativo di edificare sulla terra la Gerusalemme celeste (cfr. M. BETTETINI, Tre città in una Storia: il De civitate Dei, in Etica $\mathcal{E}$ Politica/Ethics $\mathcal{E}$ Politics, XVI [2014], 1, specialmente nr. 7, p. 455).

${ }^{124}$ Ciu., XVIII, 1.

125 Si noti la presenza del femminile qua e non del neutro quo. La stessa chiarezza letteraria non si riscontra nelle versioni italiane. Si pensi a quella di L. Alici, che così traduce: "[...] la città di Dio e la città di questo mondo, in cui anche quella, appartenendo al genere umano, è pellegrina" (AURELIO AGOSTINO, La città di Dio, cit, p. 857). Così, 
E non potrebbe essere diversamente, per due ragioni: innanzitutto, perché gli angeli (tanto quelli buoni quanto quelli cattivi) sono sottratti alla condizione precaria in cui versa il genere umano, avendo essi compiuto una scelta irrevocabile ${ }^{126}$ all'inizio della storia; in secondo luogo, perché tutta l'umanità appartiene, per generazione, alla grande massa di dannati, a causa del peccato originale, al quale si può rimediare solo per il tramite del battesimo che, per l'appunto, viene impartito nel saeculum ${ }^{127}$. Soltanto con la fine del mondo (la fine del saeculum) avverrà la definitiva separazione del genere umano, con la distinzione tra gli uomini beati e quelli dannati e con il ricongiungimento con i corrispettivi angeli ${ }^{128}$.

\section{9 - L'identificazione della CD con la Chiesa}

A fronte di tale disamina, non pare eludibile la questione dell'identificazione tra la $\mathrm{CD}$ e la Chiesa: su ciò la dottrina ha discusso ampiamente, prendendo posizioni diversificate l'una rispetto all'altra ${ }^{129}$; si

si potrebbe comprendere che la $\mathrm{CD}$ è pellegrina in questo mondo e non nella città di questo mondo. Si noti, sempre a tal proposito, che non pare esatto affermare che la $\mathrm{CD}$ appartiene al genere umano, poiché essa consta anche degli angeli buoni.

126 Che dall'inferno non vi sia ritorno, emerge dallo stesso Vangelo (cfr. Vangelo secondo Luca 16,26). In particolare, sull'irrevocabilità della scelta degli angeli, cfr. Catechismo della Chiesa cattolica, Libreria Editrice Vaticana, Città del Vaticano, 1992, p. 112, nr. 393.

127 Sul ruolo del battesimo, cfr. infra, par. 9.

${ }^{128}$ Già in Gn. litt., XI, 15 CSEL, Agostino scrive: “[...] altera coniuncta angelis bonis in rege suo uitam consequatur aeternam, altera coniuncta angelis malis in ignem cum rege suo mittatur aeternum".

129 Cfr. A. TRAPÈ, Introduzione. Teologia, cit., II.2.4.3, pp. LXXVI-LXXIX. Vi è chi afferma l'impossibilità di identificare perfettamente lo Stato con la CS e la Chiesa con la CD (cfr. V. GIORGIANNI, Il concetto del diritto, cit., IV.2, p. 119; L. ALICI, Introduzione, cit., nr. 7, p. 33), mentre altri ammettono tale duplice identificazione, ma solo retoricamente e/o practically speaking (cfr. H.-I. MARROU, Civitas Dei, cit., p. 416 s.). Inoltre, comunemente, si trovano affermazioni del seguente tenore: "La Chiesa terrena, come istituzione, è portatrice dei valori della città di Dio, ma non tutti in essa appartengono a questa città: l'identificazione si può fare - e spesso Agostino la fa - solo in un senso determinato, che è quello spirituale ed escatologico, in quanto, in tal senso, la Chiesa abbraccia tutti e solo gli eletti. Meno ancora si può identificare lo Stato con la città del diavolo" (A. TRAPÈ, S. Agostino, cit., cap. XXX, p. 325). Cotta, in particolare, rigetta l'identificazione tra CS e Stato (cfr. S. COTTA, Introduzione. Politica, cit., II.4, p. CLI). Gilson, pur mettendo in guardia dall'identificare la CS con ogni Stato terrestre, ritiene classificabile l'impero romano della decadenza con la città malvagia (cfr. É. GILSON, Les métamorphoses de la cité de Dieu, cit., II, p. 94); quanto all'identificazione fra CD e Chiesa, 
potrebbe pensare che sia inevitabile, a fronte della complessità del $D c D$, che coesistano letture financo contraddittorie, ma, oggettivamente, il tema de quo non risulta un punto di secondaria importanza130. Ecco, allora, che

reputa che si tratti di una degenerazione della dottrina agostiniana (cfr. É. GILSON, Les métamorphoses de la cité de Dieu, cit., p. 111 s.), salvo riscontrare alcune occorrenze che vanno proprio nel senso contestato (cfr. É. GILSON, Les métamorphoses de la cité de Dieu, cit., p. 97, nt. 43): "[...] come quelli che vivono nel mondo secondo il mondo sono già membri della città terrena, quelli che vivono nella Chiesa secondo la Chiesa regnano già con Cristo nel regno dei cieli" (É. GILSON, Les métamorphoses de la cité de Dieu, cit., p. 97). Ma quest'ultima affermazione non pare corretta, in quanto non considera il ruolo della predestinazione che vince qualunque condizione contingente. Fortin è radicale: "Sebbene Agostino di quando in quando equipari la città di Dio alla Chiesa [...], da altre affermazioni risulta chiaro che nessuno, che ufficialmente è un membro della Chiesa, appartiene alla città santa e che invece ne sono membri, pur senza esserne consapevoli, molti che non professano la fede cristiana" (E.L. FORTIN, Civitate Dei, cit., p. 413). Tuttavia, non pare pienamente condivisibile, laddove nega che chi appartenga alla Chiesa appartenga anche alla CD: è vero che l'adesione alla prima non è condizione sufficiente per l'adesione alla seconda, ma nessuno può appartenere alla seconda senza appartenere anche alla prima. Lamirande, invece, distingue, correttamente, tra l'appartenenza provvisoria e quella definitiva, e conclude: "On ne peut guère aller au-delà si on respecte la terminologie d'A." (cfr. E. LAMIRANDE, Ciuitas dei, cit., nr. 8, p. 963 s.). Per quanto riguarda, poi, l'identificabilità della Chiesa con la $\mathrm{CD}$, l'Autore dedica articolate riflessioni, dalle quali emerge la necessità di distinguere tra il livello terreno e quello celeste: se, da un lato, non paiono esserci problemi per la relazione tra Chiesa celeste e la $\mathrm{CD}$ in cielo (dove vige la piena identificazione), a livello terreno Agostino sembra essere più problematico e gli interpreti finiscono per sviluppare certe affermazioni del Vescovo, per evitare la piena coincidenza tra Chiesa e CD sulla terra, alla luce della presenza dei malvagi nella Chiesa (cfr. E. LAMIRANDE, Ciuitas dei, cit., nr. 10, p. 965 s.). Osserva Barr: «There is obviously some sort of "identification" between Saint Augustine's City of God and the visible Catholic Church. Several passages make this evident. [...] it is so clear that the visible Church cannot be altogether the same with the City of God [...]. Here are the clearest reasons for a real distinction (at least partial) between the two groups:1. Not every member of the visible Church is predestined to heaven. But citizenship in the City of God is by predestination. 2. Some of the members of other religions, even among the enemies of the Church and even before the time of Christ, are members of the City of God. Of course, the contrary error is equally to be avoided - the exclusion of the visible, hierarchical Catholic Church from any correlation with the City of God» (R.R. BARR, The Two Cities in Saint Augustine, cit., p. 223 s.).

130 J. RATZINGER, Die Einheit der Nationen, cit., 3.IV, p. 104, nt. 4, riconduce il rifiuto di leggere, nel $D c D$, un'equiparazione tra Città di Dio e Chiesa al perdurante influsso del pensiero idealistico. Una dimostrazione dell'attuazione dell'impianto dialettico si può ravvisare nelle seguenti parole: "La cultura tardo-medioevale aveva come centro motore la visione della Città di Dio; la società moderna si è costituita perché la gente era mossa dalla visione dello sviluppo della Città Terrena del Progresso. Nel nostro secolo, tuttavia, questa visione è andata deteriorandosi, fino a ridursi a quella della Torre di Babele, che ormai comincia a crollare e rischia di travolgere tutti nella sua rovina. Se la Città di Dio e 
occorre partire dal riconoscimento che, nell'Opera, coesistono occorrenze testuali che sembrano smentirsi, nel senso che, in alcuni passi, Agostino identifica la Chiesa con la CD, mentre, in altri, pare introdurre delle difformità tra le due.

Quanto alla prima categoria, plurimi sono i passaggi rilevanti ${ }^{131}$, come quando l'Autore si riferisce "[...] ad Christum et eius ecclesiam, quae ciuitas Dei est"132. Quanto alla seconda categoria, il discorso è più complesso: infatti, formalmente, non pare che Agostino manifesti apertamente alcuna negazione dell'identità tra Chiesa e CD - almeno non con la medesima chiarezza con cui, viceversa, la afferma -. Piuttosto, si trovano plurime occorrenze ove l'Autore, implicitamente, induce il lettore ad assumere siffatta posizione, mettendo in luce il male presente nella Chiesa133; detto altrimenti, è l'interprete che si trova spinto a dubitare che Chiesa e CD siano la stessa cosa. Ad esempio, si parla "[...] de malis et fictis, qui sunt in ecclesia, donec perueniant ad tantum numerum, qui

la Città Terrena costituiscono la tesi e l'antitesi, una nuova sintesi rappresenta l'unica alternativa al caos: la sintesi tra il nucleo spirituale del mondo tardo-medioevale e lo sviluppo, avvenuto a partire dal Rinascimento, del pensiero e della scienza. Questa sintesi costituisce la Città dell'Essere" (E. FROMM, To Have or to Be?, cit., 3.IX, p. 262). Marrou, sinteticamente, enuncia il problema: «Da una parte è ben vero che la Chiesa è il popolo dei "santi chiamati" - noi abbiamo glossato "chiamati ad esser santi" -, e lo Spirito è là che l'assiste e prevarrà sempre in essa sulle potenze dell'Ade; dall'altra non è men vero ahimè che essa appare, a giudicarla empiricamente, soprattutto composta di peccatori e di carnali, senza parlare degli ignoranti la cui buona volontà alla fine si rivela sterile per mancanza di competenza tecnica, e di maldestri che sbagliano obiettivo, abili solo a lasciarsi scappare l'occasione storica» (H.-I. MARROU, Théologie de l'histoire, cit., I.17, p. 101).

${ }^{131}$ Le occorrenze in tal senso non sono limitate al $D c D$, bensì sono rinvenibili in varie altre opere, come quando, in occasione di uno scambio epistolare, in risposta alle richieste del suo interlocutore ("et de ecclesia, quae sit, de qua scriptum est non habere rugam neque maculam, utrum haec sit, in qua nunc congregamur, an illa, quam speramus; quidam autem posuit ecclesiam hanc esse, in qua nunc frequentamus populos, et sine peccato esse non posse" [ер., CLVI CSEL]), Agostino ribadisce: "[...] quid etiam de ecclesia Christi in hoc saeculo sentiam, id est quia usque ad huius saeculi finem necesse est portet bonos et malos [...]" (ep., CLVII, 4, 40 CSEL. Va detto, però, che qui non pare pienamente soddisfacente la risposta, rispetto alle domande formulate).

132 Ciu., XVI, 2. Similmente: "[...] ciuitatem Dei, hoc est eius ecclesiam [...]" (ciu., XIII, 16); ciu. VIII, 24 e XX, 11. In altri casi, l'equazione è tra Chiesa e regnum Dei: cfr. ciu., XX, 9. Si deve notare, infine, che, addirittura, in un caso, Agostino ritiene che i malvagi giungano, in forza dei sacramenti, ad appartenere alla stessa CD, quindi identificata pienamente con la Chiesa (cfr. ciu., I, 35).

133 Ciò emerge non solo dal $D c D$ : "[...] esse intus in Ecclesia et bonos et malos [...]" (s., LXXXVIII, XVIII, 19 PL). Cfr. anche breuic., III, 8, $10 \mathrm{s.}$ 
Antichristo magnum populum faciat"134; inoltre "[...] exierunt multi haeretici de medio ecclesiae" in quanto non appartenenti a Cristo ${ }^{135}$. Dunque, pare evidente che, per Agostino, non mancano i malvagi nella Chiesa, ma essi, appunto, non sono di Cristo (detto altrimenti, non sono cittadini della $C D$ ): per conseguenza implicita, allora, non si potrebbe equiparare la Chiesa alla CD.

Ecco che entrambe le categorie di occorrenze affermano ciascuna una posizione che non pare conciliabile con l'altra. Su questo punto, come primo tentativo di spiegazione, si consideri che, a fronte di tale differenza, se la $\mathrm{CD}$ coincide con la Chiesa, allora la CS è tutto ciò che è diverso dalla Chiesa e, quindi, si accentua maggiormente la contrapposizione all'interno del mondo; se, viceversa, non c'è coincidenza, allora nella Chiesa ci sono manifestazioni di male che impediscono siffatta identificazione e, inoltre, consentono di (ri)valutare le istituzioni umane.

Non può essere dimenticato nemmeno che il $D c D$ è stato iniziato quando Agostino "[...] aveva terminato da tempo la controversia manichea, stava portando a termine quella donatista e aveva dato appena inizio a quella pelagiana, che si svolgerà, poi, pari passo con la composizione di essa"136. Quindi, l'Opera, per così dire, sconta esigenze apologetiche non limitabili alla controversia anti-pagana, testimoniando, anzi, una sensibilità già ecclesiologica, cioè una riflessione sullo statuto della Chiesa ${ }^{137}$. Ecco che, allora, il $D c D$ potrebbe essere visto come una sedimentazione di plurimi ambiti di riflessione e ciò parrebbe spiegare la discrasia tra le varie citazioni.

Ma si tratta veramente di occorrenze contraddittorie? Non è possibile dare una lettura sistematica ${ }^{138}$ ? In realtà, già Agostino sembra

134 Ciu., XX, 19.

135 Ciu., XX, 19.

136 A. TRAPÈ, Introduzione. Teologia, cit., I.3.3, p. XXVII.

137 "L'opposizione antimontanista prima, e poi la polemica antidonatista avevano condotto Agostino a fondare la dottrina delle due città sull'ecclesiologia, di cui essa rimane un assai rilevante aspetto. Per essere più esatti, la dottrina delle due città si sviluppa parallelamente alla ecclesiologia" (A. VECCHI, Introduzione al De Civitate Dei, cit., p. 36 s.).

138 Alcuni autori ritengono inesigibile la coerenza sistematica in Agostino. Ad esempio, Barr osserva: "Thus the City of God, like an Aristotelian quality, is usually represented as pure in itself but scattered or diluted when considered in its place in physical reality. Once, however, the City of God is described as harboring some of the nonpredestined within its very ranks [...]. The explanation is that Saint Augustine is not a systematizer, and that here, simply and without warning, he is speaking of the City of God in its "looser" sense, probably as synonimous with the Church" (R.R. BARR, The 
fornire una prima visione organica, laddove distingue tra la CD beata e quella peregrinante, precisamente sin dall'inizio dell'Opera: "Gloriosissimam ciuitatem Dei siue in hoc temporum cursu, cum inter impios peregrinatur ex fide uiuens, siue in illa stabilitate sedis aeternae, quam nunc exspectat per patientiam"139.

Accanto a ciò, si ha la distinzione tra la Chiesa terrestre e quella celeste, ossia tra la Chiesa che vive nel mondo (al tempo di Agostino come adesso) e quella che è sottratta ai condizionamenti mondani:

“Numquid de regno illo, ubi nulla sunt scandala? De isto ergo regno eius, quod est hic ecclesia, colligentur. [...] Alio modo igitur intellegendum est regnum caelorum, ubi ambo sunt, et ille scilicet qui soluit quod docet, et ille qui facit; sed ille minimus, ille magnus: alio modo autem regnum caelorum dicitur, quo non intrat nisi ille qui facit. Ac per hoc ubi utrumque genus est, ecclesia est, qualis nunc est; ubi autem illud solum erit, ecclesia est, qualis tunc erit, quando malus in ea non erit. Ergo et nunc ecclesia regnum Christi est regnumque caelorum"140.

Tra le due articolazioni non sembra esserci alcuna vera differenza, a parte, per l'appunto, l'influenza del male, tant'è che esse sono definite unitariamente sancta Ecclesia ${ }^{141}$.

Two Cities in Saint Augustine, cit., p. 223, nt. 4). Per questo, conclude: "We must beware of requiring too much scientific exactness of Saint Augustine's rhetorical presentation, but we shall be able to make some precisions" (R.R. BARR, The Two Cities in Saint Augustine, cit., 226, nt. 4). Parimenti, Marrou afferma: "Saint Augustin n'élabore pas des concepts, définis more geometrico une fois pour toutes et qu'il utiliserait ensuite pour construire un système synthétique définitif; il se sert de mots qui, enrobés dans un contexte littéraire et dialectique déterminé, doivent faire naître telle conviction dans l'esprit du lecteur, hic et nunc, - et peu lui importe si ailleurs, dans un autre contexte, les mêmes mots devront être pris dans un autre sens" (H.-I. MARROU, Civitas Dei, cit., p. 415 s.).

$$
\begin{aligned}
& { }^{139} \text { Ciu., I, praef. } \\
& { }^{140} \text { Ciu., XX, } 9 .
\end{aligned}
$$

141 "Quae tota hic accipienda est, non solum ex parte qua peregrinatur in terris [...], uerum etiam ex illa quae in caelis semper ex quo condita est cohaesit deo, nec ullum malum sui casus experta est. Haec in sanctis angelis beata persistit, et suae parti peregrinanti sicut oportet opitulatur [...]. Ac per hoc spiritus sanctus, si creatura non creator esset, profecto creatura rationalis esset - ipsa est enim summa creatura - et ideo in regula fidei non poneretur ante ecclesiam, quia et ipse ad ecclesiam pertineret in illa eius parte quae in caelis est [...]. Templum enim dei, hoc est totius summae trinitatis, sancta est ecclesia, scilicet uniuersa in caelo et in terra. Sed de illa quae in caelo est affirmare quid possumus nisi quod nullus in eo malus est, nec quisquam deinceps inde cecidit aut casurus est" (ench., XV, 56 s.). Sulle due parti nella CD (peregrinante e adiuvante) e sugli angeli come assistenti dell'umanità sulla terra, cfr. ciu., X, 7. 
A fronte di ciò, si può affermare che, nel tempo, la Chiesa contiene tanto i buoni quanto i cattivi. Ebbene, si tratta del tema affrontato da Agostino specialmente nella polemica contro i donatisti, i quali distinguevano nettamente tra credenti probi e malvagi e, perciò, creavano non poche problematiche ecclesiologiche ${ }^{142}$. Negando che la Chiesa sia già la CD, Agostino potrebbe aver perseguito l'obiettivo di dare legittimazione concettuale alla coesistenza di buoni e cattivi: non bisognerebbe, cioè, scandalizzarsi dell'iniquità presente anche nella Chiesa, poiché quest'ultima costitutivamente raccoglie tutti ${ }^{143}$. Si capisce, allora, perché all'Autore serva una categoria ulteriore, ossia quella della $\mathrm{CD}$, nella quale non c'è spazio per il male. L'appartenenza alla comunità dei giusti, quindi, non sarebbe garantita soltanto da un aspetto formale quale il battesimo, bensì dall'imperscrutabile volontà di Dio (la predestinazione), la quale eleggerebbe alcuni e ricuserebbe altri, a prescindere dal battesimo. Ecco perché, sotto questo aspetto, non si può identificare la Chiesa con la CD.

Da un altro punto di vista, invece, non c'è dubbio che la Chiesa sia la CD, ossia che la seconda si 'esaurisca' nella prima. Il motivo pare altrettanto semplice e si riferisce sempre alle esigenze anti-donatiste: per Agostino, infatti, non vi può essere dubbio circa l'efficacia oggettiva dei sacramenti e, dunque, pare prioritario ribadire che il battesimo è la porta formale della salvezza ${ }^{144}$, a partire da Cristo in poi ${ }^{145}$. A prescindere dalla

142 Il donatismo è da ricondurre a "[...] ragioni in largo senso teologiche, sì, ma imperniate non sul problema del Cristo, bensì sulla comunità cristiana, come società religiosa e morale, e dell'episcopato, come struttura autoritaria" (G. TABACCO, Le metamorfosi della potenza sacerdotale nell'alto medioevo, a cura di G.G. MERLO, Morcelliana, Brescia, 2012, I.5, p. 31). Non si dimentichino, comunque, anche le problematiche che insorgeranno, molti secoli dopo, con l'influenza della sensibilità protestante, per la quale la contrapposizione è proprio tra fede e incredulità, in chiave anti-gerarchica: cfr. L. ALICI, Introduzione, cit., nr. 7, p. 33 e relativa nt. 128.

143 Dire ciò non è lo stesso che parlare di una Chiesa quale corpus bipartitum, come fa Ticonio (cfr. G. AGAMBEN, Il mistero del male. Benedetto XVI e la fine dei tempi, Laterza, Roma-Bari, 2013, I. Il mistero della Chiesa, pp. 5-19).

144 Detto altrimenti, l'assenza di battesimo causa inevitabilmente la dannazione, a prescindere dal fatto che la persona sia in condizione o meno di scegliere. Al più, Agostino riconosce che i bambini morti senza battesimo subiranno una damnatio omnium levissima (cfr. c. Iul., V, XI, 44 PL). Vi è, poi, chi, come Giorgianni, ravvisa, nel pensiero del Vescovo, una traccia di etica naturale (cfr. V. GIORGIANNI, Il concetto del diritto, cit., V, p. 168 s.); il testo di riferimento, però, attesta soltanto che coloro che siano privi della grazia di Cristo possono sì compiere opere naturaliter secondo la legge, ma ciò non eviterà loro la dannazione, bensì garantirà loro soltanto una pena minore (cfr. spir. et litt., XXVIII, 48 CSEL). 
presenza di malvagi nelle gerarchie ecclesiastiche (id est, anche tra i ministri che impartiscono il battesimo), il sacramento de quo è valido e, soprattutto, essenziale per la vita beata. Quindi, nella dimensione dell'eternità, non c'è dubbio, per Agostino, che tutti (e solo) i battezzati siano in possesso delle credenziali per la CD.

Come si può notare, ambedue le posizioni rispondono a esigenze legittime e nobili e, quindi, si può capire il perché della loro coesistenza nella medesima opera. Ma sono veramente compatibili? Non si tratta di soluzioni confliggenti146? Per risolvere tale dubbio non resta che immaginare la contestuale applicazione di ambedue le teorie ${ }^{147}$.

145 Naturalmente, Agostino non esclude la salvezza per coloro che sono nati prima di Cristo, se ebrei: "Ora la religione cosiddetta cristiana era presente nell'umanità prima che il Cristo s'incarnasse, solo che allora non era che una religione virtualmente universale, praticata dapprima da un solo uomo, poi da una sola famiglia, poi da una sola tribù, e infine da un solo popolo" (J. GUITTON, Attualità di Sant'Agostino, cit., p. 55). Più in generale, si tratta del tema della differenza tra res e nomen: "Nam res ipsa, quae nunc christiana religio nuncupatur, erat et apud antiquos nec defuit ab initio generis humani, quousque ipse Christus ueniret in carne, unde uera religio, quae iam erat, coepit appellari christiana" (retr., I, 13, 3). Ma sembra possibile anche una salvezza universale per chiunque abbia creduto, in qualche modo, in Cristo e, dunque, anche al di fuori della stirpe eletta (cfr. ep., CII, 2, 12; J. GUITTON, Attualità di Sant'Agostino, cit., pp. 54-56). Una conferma di ciò si ha in riferimento al personaggio di Giobbe (cfr. ciu., XVIII, 47). Tuttavia, non pare possibile aderire alla tesi di Barr, il quale ritiene che, nella CD, vi siano anche uomini "from various religious and moral systems" (cfr. R.R. BARR, The Two Cities in Saint Augustine, cit., p. 212), e ciò proprio verificando i passi citati dall'Autore nella relativa nt. 11. In ciu., XIV, 1, infatti, si parla di diuersis ritibus - dove, invece, Agostino, per indicare il concetto di religione, usa religio (cfr., e pluribus, ciu., I, 36) e non solo in riferimento al cristianesimo (cfr., e pluribus, ciu., IV, 32) -; inoltre, in ogni caso, da tale passaggio non si può in alcun modo inferire che, da coloro che restano fedeli ai diversi riti e/o religioni, vengano tratti membri della CD. Quanto alla questione della ascrivibilità della Sibilla cumana alla CD, in ciu., X, 27, Agostino non afferma nulla in tal senso, mentre, in ciu., XVIII, 23, prospetta la mera possibilità di tale soluzione ("ita [...] loquitur, ut in eorum numero deputanda uideatur, qui pertinent ad ciuitatem Dei").

146 Una possibile lettura conciliante pare essere la seguente: «Una gerarchia sacerdotale, così intimamente partecipe delle responsabilità generali di comando e così definitivamente strutturata come organismo giuridico, in tanto era possibile in quanto la società stessa cristiana rinunziava ormai a presentarsi come 'chiesa di santi'. Il grande avversario dei donatisti, Agostino, si rassegnava ormai a distinguere entro la chiesa corpo di Cristo [...], entro cioè la comunità universale dei credenti e partecipanti ai riti sacramentali, una chiesa di santi più occulta, commista, nella cristianità visibile, con una chiesa di peccatori. Così intesa come "corpus permixtum", la chiesa poteva dunque coincidere, anche concettualmente, con l'intera società retta dal connubio politicosacerdotale» (G. TABACCO, Le metamorfosi della potenza sacerdotale, cit., I.5, p. 33).

147 Va notato che Trapè distingue tre modi di declinare la realtà cristiana: istituzionale, 
Si parta dalla tesi che nega la coincidenza tra Chiesa e CD. Presupponendo che Chiesa qui valga per Chiesa nel tempo, la difformità comporta che non si possa identificare automaticamente i membri della Chiesa visibile con i cittadini celesti. Esplicando, significa che non tutti i battezzati appartengono alla società celeste: il battesimo, però, è valido e produce i suoi effetti con l'incardinazione nella comunione militante; tra i battezzati vi sono, infatti, anche tre categorie incompatibili con la vita beata perché non predestinate da Dio (i falsi credenti, i credenti che non agiscono rettamente e i credenti che agiscono rettamente ma non sono predestinati a perseverare) ${ }^{148}$.

A questo punto, si provi a sostenere contestualmente la tesi della coincidenza tra Chiesa e CD. Presupponendo che Chiesa qui valga per Chiesa nell'eternità ${ }^{49}$, l'identità piena tra $\mathrm{i}$ due soggetti comporta che tutti i membri di siffatta Chiesa siano anche cittadini celesti. Esplicando, l'attenzione in questo caso non è posta sul battesimo, bensì sulla predestinazione: chiaramente predestinazione a essere battezzati - poiché senza siffatto sigillo nessun uomo può accedere al regno dei cieli -, ma non solo. Infatti, tutte e tre le categorie suddette - relative a uomini battezzati sono accomunate dall'assenza di predestinazione alla perseveranza, rispettivamente: nella fede, nelle opere attuali, nella fede e/o nelle opere

spirituale ed escatologico, dove il primo è la communio sacramentorum, il secondo è la communio sanctorum, il terzo è la communio praedestinatorum. La prima comprende buoni e cattivi, la seconda solo i buoni che peregrinano in ogni tempo, la terza solo i buoni che hanno raggiunto la meta finale. Si tratta, comunque, della medesima realtà in forme diverse (cfr. A. TRAPÈ, Introduzione. Teologia, cit., II.2.4.3, p. LXXVII).

148 Queste categorie paiono essere la concretizzazione di quanto previsto in ciu., I, 35, ove emerge chiaramente che vi sono persone validamente battezzate che, però, non sono predestinate alla salvezza.

${ }^{149} \mathrm{Si}$ noti che, però, almeno in due passaggi, la riflessione in questione potrebbe essere contestata, in quanto Agostino sembra identificare la CD anche con la Chiesa visibile, nel tempo: "Aedificatur enim domus Domino ciuitas Dei, quae est sancta ecclesia, in omni terra post eam captiuitatem, qua illos homines, de quibus credentibus in Deum tamquam lapidibus uiuis domus aedificatur, captos daemonia possidebant" (ciu., VIII, 24). "[...] non utique ad unum locum uenisse uel uenturi esse significati sunt, quasi uno aliquo loco futura sint castra sanctorum et dilecta ciuitas, cum haec non sit nisi Christi ecclesia toto terrarum orbe diffusa; ac per hoc ubicumque tunc erit, quae in omnibus gentibus erit, quod significatum est nomine latitudinis terrae, ibi erunt castra sanctorum, ibi erit dilecta Deo ciuitas eius [...]" (ciu., XX, 11). In realtà, tali citazioni non si riferiscono espressamente all'articolazione ecclesiastica umana, ben potendo essere lette in relazione alla Chiesa di Cristo che si espande su tutta la terra. 
de futuro ${ }^{150}$. Inoltre, si aggiunga la categoria di coloro che, nel tempo, non sono ancora battezzati: ebbene, costoro, pur mancando, in atto, del Sigillo, sono comunque già cittadini celesti, poiché predestinati da Dio a ricevere, almeno in punto di morte, il battesimo (detto altrimenti, anche se, attualmente, sono senza grazia e risultano dannati, in realtà, per la misericordia di Dio, eviteranno la morte almeno fino a quando non saranno stati battezzati e, quindi, sono, sub specie aeternitatis, salvi) ${ }^{151}$.

L'unico punto che pare sfuggire alla suddetta sistematizzazione è collegato agli angeli: come già visto, codesti sono spartiti, al pari degli uomini, tra CD e CS. Ebbene, se la CD comprende anche gli angeli buoni, come è possibile identificare pienamente la Chiesa celeste con essa? Vi è, infatti, chi nega tale possibilità (anche) considerando il fatto che gli angeli non sarebbero membri della Chiesa ${ }^{152}$. Ora, malgrado risulti innegabile

150 Non si può, cioè, affermare in modo assoluto quanto segue: "nonpredestined Catholics are not living according to the Church" (R.R. BARR, The Two Cities in Saint Augustine, cit., p. 225). Infatti, un non-predestinato potrebbe abbandonare la fede anche soltanto sul letto di morte, dopo una vita integerrima.

151 In conclusione, si deve, comunque, notare che mentre la CD è sempre la stessa, tanto nel tempo quanto nell'eternità, lo stesso non si può dire della Chiesa: quest'ultima, nel saeculum, è certamente più ampia di quello che è nella dimensione già beata, in quanto comprende anche i validamente incardinati che, però, non sono predestinati alla salvezza. Di modo che è possibile stabilire la seguente identità: CD nell'eternità = CD nel tempo = Chiesa nell'eternità. Non pare pienamente inquadrabile in siffatta categorizzazione il seguente passo: "Meminerit sane in ipsis inimicis latere ciues futuros, ne infructuosum uel apud ipsos putet, quod, donec perueniat ad confessos, portat infensos; sicut ex illorum numero etiam Dei ciuitas habet secum, quamdiu peregrinatur in mundo, conexos communione sacramentorum, nec secum futuros in aeterna sorte sanctorum, qui partim in occulto, partim in aperto sunt, qui etiam cum ipsis inimicis aduersus Deum, cuius sacramentum gerunt, murmurare non dubitant, modo cum illis theatra, modo Ecclesias nobiscum replentes. De correctione autem quorundam etiam talium multo minus est desperandum, si apud apertissimos aduersarios praedestinati amici latitant, adhuc ignoti etiam sibi" (ciu., I, 35). Stando a esso, infatti, i malvagi non predestinati alla salvezza apparterrebbero direttamente anche alla CD, in forza dei sacramenti: Agostino, infatti, ivi non parla di Ecclesia, bensì proprio di civitas Dei. Il fatto, che, poi, comunque i reprobi non apparterranno, sub specie aeternitatis, alla CD non toglie che si tratti di un'occorrenza non pienamente coerente con la soluzione proposta; al più, ne risulta confermata la tendenza dell'Ipponense a utilizzare i due termini come sinonimi.

152 "Indicando fondamentalmente due comunità di amore divise dall'accettazione o dal rifiuto della verità di Cristo, le due città si esprimono anche attraverso istituzioni storiche visibili, senza però coincidere integralmente con esse; non si può quindi porre una equazione perfetta, come invece sovente si è fatto, tra la città di Dio e la Chiesa, da un lato, e tra la città terrena e lo Stato, dall'altro. Anzitutto, anche se la Chiesa è il regno di Cristo nel tempo, edificato sul fondamento della fede, esiste una doppia differenza 
che la modalità per aderire a essa, prevista per gli uomini, non sia estensibile agli angeli (i quali, infatti, non possono venire battezzati), pare che, comunque, anche questi ultimi appartengano alla Chiesa, secondo Agostino: non a quella visibile ${ }^{153}$, bensì a quella invisibile, celeste, ossia a quella che vive già nell'eternità ${ }^{154}$. E tale comune militanza non sembra soltanto una posizione dottrinale del Vescovo, bensì risulta anche dalle Scritture, che sottolineano la soggezione di angeli e uomini a Cristo e, tramite lui, alla Chiesa ${ }^{155}$. Pertanto, l'impianto sistematico presentato non sembra sconfessabile in relazione alla categoria angelica, anzi ne risulta confermato.

\section{0 - La predestinazione quale criterio di ascrizione alle due civitates ${ }^{156}$}

Da tale sistema ermeneutico emerge nitidamente come, in realtà, il vero discrimine per appartenere alla CD non sia tanto il battesimo, quanto la predestinazione alla perseveranza: se è vero che nessuno può salvarsi senza essere battezzato, è altrettanto vero che non basta il battesimo per essere automaticamente cittadini del cielo, poiché solo chi è predestinato a rimanere nella grazia di Cristo è salvo; e predestinato a ciò può essere anche un uomo non ancora battezzato.

rispetto alla città di Dio; in un senso infatti la Chiesa è solo una parte della città di Dio, la quale abbraccia anche gli angeli e la comunità celeste dei santi, che anzi ne costituiscono la magna pars; in un altro senso la Chiesa, in quanto popolo dei credenti che attende nella fede, nella speranza e nell'amore la purificazione finale, in cui quindi il grano è ancora misto a zizzania, delinea un ambito più vasto rispetto a quella parte della città di Dio che è ancora pellegrina; tutti i cittadini della città di Dio pellegrina appartengono alla Chiesa, ma non viceversa" (L. ALICI, Introduzione, cit., nr. 7, p. 33).

153 Che è pensata appositamente per gli uomini e richiede una dimensione materiale. Lo si capisce dal seguente passo: "Ierusalem in Babylonia captiua tenebatur non tota: ciues enim eius et angeli sunt" (en. Ps., CXXXVI, 1).

154 "in ipsis angelis sanctis per ecclesiam multiformis sapientiae dei, cum quibus post hanc peregrinationem sine labore et sine fine uiuendum est" (Gn. litt., XII, 28 CSEL). Cfr. anche ench., XV, 56: "Haec in sanctis angelis beata persistit, et suae parti peregrinanti sicut oportet opitulatur [...]. Ac per hoc spiritus sanctus, si creatura non creator esset, profecto creatura rationalis esset - ipsa est enim summa creatura - et ideo in regula fidei non poneretur ante ecclesiam, quia et ipse ad ecclesiam pertineret in illa eius parte quae in caelis est".

155 "Tutto infatti egli ha messo sotto i suoi piedi e lo ha dato alla Chiesa come capo su tutte le cose" (Lettera agli Efesini 1,22, secondo la traduzione in La Bibbia di Gerusalemme, EDB, Bologna, 2009, p. 2783). Cfr. anche Lettera ai Colossesi 2,10.

156 In generale, sull'ascrizione alle due città, cfr. L. ALICI, Introduzione, cit., nr. 7. 
Nemmeno può ritenersi veramente rilevante il tema dell'amore, nel senso che sarebbe decisiva la scelta del singolo individuo, in relazione alle sorti eterne di quest'ultimo. Ora, a ben vedere, due amori hanno certamente segnato la nascita delle due città: "Fecerunt itaque ciuitates duas amores duo, terrenam scilicet amor sui usque ad contemptum Dei, caelestem uero amor Dei usque ad contemptum sui"157. Parimenti i medesimi hanno un indubbio rilievo anche nello sviluppo della CD e della CS158, ma tutto questo non sembra cancellare il tema della predestinazione, anzi lo conferma, nel senso che risulta cardinale capire se si tratti di amori liberamente orientabili o se, viceversa, si tratti di manifestazioni umane della predeterminata elezione divina.

Nonostante non manchino voci dissenzienti ${ }^{159}$, pare innegabile che, per Agostino, sia Dio a stabilire le civitates di appartenenza: "hoc est duas societates hominum, quarum est una quae praedestinata est in aeternum regnare cum Deo, altera aeternum supplicium subire cum diabolo"160. Dunque, malgrado tutti i tentativi di 'disinnescare' la portata della

${ }_{157}$ Ciu. XIV, 28. Nello stesso senso, cfr. en. Ps., LXIV, 2.

158 "Hi duo amores - quorum alter sanctus est, alter immundus, alter socialis, alter priuatus, alter communi utilitati consulens propter supernam societatem, alter etiam rem communem in potestatem propriam redigens propter adrogantem dominationem, alter subditus, alter aemulus deo, alter tranquillus, alter turbulentus, alter pacificus, alter seditiosus, alter ueritatem laudibus errantium praeferens, alter quoquo modo laudis auidus, alter amicalis, alter inuidus, alter hoc uolens proximo quod sibi, alter subicere proximum sibi, alter propter proximi utilitatem regens proximum, alter propter suam praecesserunt in angelis, alter in bonis, alter in malis, et distinxerunt conditas in genere humano ciuitates duas sub admirabili et ineffabili prouidentia dei cuncta, quae creat, administrantis et ordinantis, alteram iustorum, alteram iniquorum. quarum etiam quadam temporali conmixtione peragitur saeculum, donec ultimo iudicio separentur, et altera coniuncta angelis bonis in rege suo uitam consequatur aeternam, altera coniuncta angelis malis in ignem cum rege suo mittatur aeternum. de quibus duabus ciuitatibus latius fortasse alio loco, si dominus uoluerit, disseremus" (Gn. litt., XI, 15 CSEL).

${ }^{159}$ M. BETTETINI, Tre città in una Storia, cit., nr. 5, p. 450, ritiene che le creature siano state dotate "[...] della possibilità di scegliere di quale civitas essere cittadino".

${ }_{160}$ Ciu., XV, 1; cfr., altresì, ciu., I, 35 (il testo è citato supra, nt. 151). Anche in en. Ps., LXIV , 2, risulta determinante, malgrado la chiamata alla conversione in capo ai cittadini di Babilonia, il ruolo della predestinazione. Nella stessa dottrina non mancano alcune perplessità a considerare i duo amores quali fondamento del sistema del $D c D$ : cfr. M.A. RASCHINI, La problematica politica, cit., IV, p. 99. Senza contare che risulta problematica la stessa utilizzazione della categoria di amor, in relazione ai malvagi: "Come mai l'opposizione tra l'amore di sé e l'amore di Dio, se è vero che solo l'amore di Dio è autentico amore di sé?" (A. TRAPÈ, S. Agostino, cit., cap. XXX, p. 315). 
predestinazione per l'Ipponense ${ }^{161}$, non sembra negabile che l'ascrizione alle due città sia da ricondurre, da ultimo, alla volontà divina ${ }^{162}$; paradossalmente, ad esempio, ci potrebbe essere il caso di chi rivolge veramente il suo amore verso Dio, ma ciò non implicherebbe automaticamente che costui sia da annoverare tra gli eletti, poiché ben potrebbe non perseverare nella sua intenzione ${ }^{163}$ e tale mutamento non dipenderebbe da lui.

Si potrebbe obiettare che, talora, il Vescovo non parla di predestinazione, bensì di praescientia, in ciò potendosi vedere una dimensione passiva in capo a Dio, che si 'limiterebbe' a conoscere prima le condotte degli uomini, senza coartarle ${ }^{164}$. Ora, certamente è vero che Dio

161 Cfr. A. TRAPÈ, Introduzione. Teologia, cit., II.2.4.5, p. LXXXI s. Barr riconosce che, in Agostino, la predestinazione è non meritoria ("Ultimately, the only title to citizenship in this glorious state is not merit, but the altogether gratuitous predestination of God's grace" [R.R. BARR, The Two Cities in Saint Augustine, cit., p. 215]); tuttavia, precisa subito: "The human members of the City of the Devil are all those who, because of freely chosen sin, are not predestined to heaven" (R.R. BARR, The Two Cities in Saint Augustine, cit., p. 215). Sempre secondo Barr, nulla nell'Ipponense farebbe propendere per una predestinazione arbitraria: "The author has found nothing in Saint Augustine asserting a positive divine reprobation" (R.R. BARR, The Two Cities in Saint Augustine, cit., p. 215, nt. 10). In realtà, basta leggere quanto Agostino scrive in relazione all'operato di Satana, per vedere come predestinazione e peccato siano in rapporto di causa-effetto, la prima rispetto al secondo (cfr. ciu., XX, 7, specialmente: "Nam seducere illum gentes etiam nunc et secum trahere in aeternam poenam, sed non praedestinatas in aeternam uitam").

162 "Se vogliamo intendere il titolo stesso De Civitate Dei, dobbiamo tenere ben distinti i due aspetti. Da una parte c'è il nostro esser scelti da Dio; dall'altra il nostro edificare la Chiesa nel mondo. Per la salvezza del mondo, è necessario che il mondo sia trasfigurato in Chiesa visibile: ma tale trasfigurazione può avvenire solo ove si sia già almeno in radice d'anima estranei agl'interessi del mondo, ove cioè si sia già stati scelti come peregrini al mondo e quindi innanzitutto giustificati nel sangue del Cristo. La predestinata appartenenza alla giustificazione fonda appunto la Città di Dio" (A. VECCHI, Introduzione al De Civitate Dei, cit., p. 40). Cfr. anche É. GILSON, Les métamorphoses de la cité de Dieu, cit., II, p. 92 s.

163 Detto altrimenti, l'intenzione con cui si compie un'azione può anche essere positiva, ma comunque non garantirebbe che il soggetto abbia la perseveranza sino alla fine. Sembra emergere una certa rilevanza quanto all'intenzione in $e p ., \mathrm{XCIII}, 7$, ma in realtà non è conferente al tema che interessa, quanto piuttosto alla punizione (intenzione di Dio/Paolo vs. intenzione di Satana): "Discamus, fratres, in similitudine operum discernere animos operantium, ne clausis oculis calumniemur et beniuolos pro nocentibus accusemus".

164 "[...] secundum Dei praescientiam exortas fuisse existimemus in genere humano societates tamquam ciuitates duas" (ciu., XII, 28). In realtà, sarebbe più corretto parlare, per Dio, di scientia, in quanto costui non soggiace ai condizionamenti temporali (cfr. Simpl., II, 2, 2, in particolare: "Quid est enim praescientia nisi scientia futurorum? Quid 
conosce ogni cosa prima che accada, senza, per ciò stesso, volere che accada, ma Agostino risulta chiaro nel ritenere che Dio agisca sulla base non della semplice prescienza, bensì attuando una vera e propria predestinazione, come si nota sin dalle promesse effettuate ai patriarchi ${ }^{165}$. E ciò pare inevitabile, nella prospettiva dell'Ipponense, in quanto, altrimenti, l'elezione - nonché, più in generale, la grazia - sarebbe esigibile da parte degli uomini in forza delle opere.

autem futurum est deo, qui omnia tempora supergreditur? Si enim scientia dei res ipsas habet, non sunt ei futurae sed praesentes; ac per hoc non iam praescientia sed tantum scientia dici potest"). Sulla piena compatibilità tra prescienza di Dio e libertà dell'uomo, cfr. J. VAN GERVEN, Liberté humaine et prescience divine d'après saint Augustin, in Revue Philosophique de Louvain, 55 (1957), pp. 317-330.

165 «Item quod dixi: "Salutem religionis huius nulli umquam defuisse qui dignus fuit, et dignum non fuisse cui defuit", si discutiatur et quaeratur unde quisque sit dignus, non desunt qui dicant, voluntate humana: nos autem dicimus, gratia vel praedestinatione divina. Inter gratiam porro et praedestinationem hoc tantum interest, quod praedestinatio est gratiae praeparatio, gratia vero iam ipsa donatio. Quod itaque ait Apostolus: Non ex operibus, ne forte quis extollatur: ipsius enim sumus figmentum, creati in Christo Iesu in operibus bonis, gratia est; quod autem sequitur: quae praeparavit Deus, ut in illis ambulemus, praedestinatio est, quae sine praescientia non potest esse; potest autem esse sine praedestinatione praescientia. Praedestinatione quippe Deus ea praescivit, quae fuerat ipse facturus: unde dictum est: Fecit quae futura sunt. Praescire autem potens est etiam quae ipse non facit; sicut quaecumque peccata: quia etsi sunt quaedam, quae ita peccata sunt, ut poenae sint etiam peccatorum, unde dictum est: Tradidit illos Deus in reprobam mentem, ut faciant quae non conveniunt; non ibi peccatum Dei est, sed iudicium. Quocirca praedestinatio Dei quae in bono est, gratiae est, ut dixi, praeparatio; gratia vero est ipsius praedestinationis effectus. Quando ergo promisit Deus Abrahae in semine eius fidem gentium, dicens: Patrem multarum gentium posui te; unde dicit Apostolus: Ideo ex fide, ut secundum gratiam firma sit promissio omni semini, non de nostrae voluntatis potestate, sed de sua praedestinatione promisit. Promisit enim quod ipse facturus fuerat, non quod homines. Quia etsi faciunt homines bona quae pertinent ad colendum Deum, ipse facit ut illi faciant quae praecepit, non illi faciunt ut ipse faciat quod promisit: alioquin ut Dei promissa compleantur, non in Dei, sed in hominum est potestate, et quod a Domino promissum est, ab ipsis redditur Abrahae. Non autem sic credidit Abraham, sed credidit dans gloriam Deo, quoniam quae promisit, potens est et facere; non ait: Praedicere; non ait: Praescire; nam et aliena facta potest praedicere atque praescire; sed ait: potens est et facere; ac per hoc facta, non aliena, sed sua» (praed. sanct., X, 19 BA). Quanto al concetto di grazia in Agostino, cfr. L. ALICI, Appendici, cit., nr. 11; A. VECCHI, Introduzione al De Civitate Dei, cit., pp. 13-36. Si ricordi, comunque, che la dottrina compiuta su tale tema è contenuta nell'Ad Simplicianum e confermata nel De peccatorum meritis et remissione (cfr. G. CATAPANO, Agostino, cit., rispettivamente, III, pp. 93-97 e VIII, p. 225 s.). 


\section{1 - Il DcD come strumento politico}

In questa sede non si intende dare contezza precisa del fenomeno del così detto agostinismo politico ${ }^{166}$, né del pessimismo agostiniano ${ }^{167}$, bensì seguire alcune tracce di riflessione che svolgano quanto previamente osservato. Ora, pare indubbio che il $D c D$ abbia influenzato il pensiero politico medievale ${ }^{168}$, venendo usato da tutte le fazioni - compresa quella anti-papale -, sovente in modo strumentale ${ }^{169}$; ma, in realtà, la concezione dell'Ipponense circa le due civitates

166 Va detto che, sul tema dell'agostinismo politico, non c'è pieno accordo, da parte degli studiosi: Cotta, ad esempio, nega che nel $D c D$ siano teorizzate delle concezioni utili per il governo, nonché che si tratti di un'opera di politica (cfr. S. COTTA, Introduzione. Politica, cit., I.1, specialmente p. CXXXV). Altri sostengono che "[...] non c'è nella proposta di Agostino una cosa come una politica cristiana. La saggezza cristiana e il potere politico possono occasionalmente coesistere in un singolo soggetto, cioè nella persona del sovrano cristiano, ma anche in questo caso essi restano distinti, cooperando fra loro ogniqualvolta è possibile, ma mai fondendosi l'uno con l'altro" (E.L. FORTIN, Civitate Dei, De, cit., p. 416). Esposito ritiene che il vero erede di Agostino non sia l'agostinismo politico, bensì il pensiero di Pascal (cfr. R. ESPOSITO, Nove pensieri sulla politica, cit., nr. 3, p. 29 s.).

167 Per riferimenti bibliografici alla corrente che legge, in Agostino, un pessimista circa la società terrena, cfr. V. GIORGIANNI, Il concetto del diritto, cit., IV.1, p. 108, nt. 2. In generale, il pensiero di Giorgianni è contrario alla lettura consistente nel radicale pessimismo agostiniano, malgrado riconosca nel Vescovo una costante richiesta della Grazia, perché lo Stato possa appartenere alla Città di Dio. In particolare, invita a distinguere tra l'ordine dell'astratto e l'ordine del concreto (cfr. V. GIORGIANNI, Il concetto del diritto, cit., IV, specialmente $\$ 2$ ). Tuttavia, pare significativa l'assenza di riferimenti, anche nella conclusione, al tema della predestinazione (cfr. V. GIORGIANNI, Il concetto del diritto, cit., V).

168 In estrema sintesi, si può notare come il pensiero di Agostino sulle due città continui a dominare nel medioevo: soltanto che, fino al Mille, vi sarebbe stata una netta distinzione tra le due città, con quella terrestre identificata nell'Impero (dualismo); successivamente, invece, con il sorgere del Sacro Romano Impero, si attesterebbe una sorta di monismo, per cui lo Stato diventa espressione della stessa civiltà cristiana (cfr. G. REALE, D. ANTISERI, Il pensiero occidentale, cit., 17.1.6, p. 369).

169 Cfr. M.C. SLOAN, De civitate Dei, cit., p. 256. In particolare, si pensi all'influenza della concezione agostiniana delle due città, in relazione al processo di secolarizzazione (cfr. E.-W. BÖCKENFÖRDE, Zum Verhältnis von Kirche und moderner Welt. Aufriß eines Problems [1977], traduzione italiana di C. BERTANI, S. BIGNOTTI, A. ANELLI, Sul rapporto tra Chiesa e Mondo moderno. Delineazione di un problema, in IDEM, Cristianesimo, libertà, democrazia, Morcelliana, Brescia, 2007, B.I.1, p. 131). Sul tema, cfr. infra, par. 12. Più in generale, sull'influenza avuta dal $D c D$ nel corso dei secoli, cfr. L. ALICI, Introduzione, nr. 9. 
"[...] non mira né ad una "ecclesializzazione" (Verkirchlichung) dello Stato né ad una "statalizzazione" (Verstaatlichung) della Chiesa, ma, in mezzo gli ordinamenti di questo mondo, che rimangono e devono restare ordinamenti mondani, aspira a rendere presente la nuova forza della fede nell'unità degli uomini nel corpo di Cristo, come elemento di trasformazione, la cui forma completa sarà creata da Dio stesso, una volta che questa storia abbia raggiunto il suo fine» ${ }^{170}$.

Ecco perché Ratzinger ritiene indebita l'ascrizione ad Agostino della paternità della concezione teocratica della Chiesa medievale: piuttosto, detta visione sarebbe dovuta a un'errata interpretazione delle tesi dell'Ipponense ${ }^{171}$. Ma il punto che qui interessa non è tanto il fraintendimento del rapporto tra Chiesa e CD presso i medievali ${ }^{172}$, quanto l'utilizzo del $D c D$ per l'emancipazione dello Stato dalla Chiesa.

Basilare risulta, come già anticipato, il seguente passo, che pare

170 J. RATZINGER, Die Einheit der Nationen, cit., 3.IV, p. 111. A tal proposito, bisognerebbe far riferimento al realismo agostiniano, "[...] il quale, vividamente distinguendo i due ordini della natura e della grazia, sempre s'era tenuto lontano dalla deificazione pelagiana della natura e dall'antico riconoscimento dello Stato quale valore assoluto, ma sempre s'era tenuto distante altresì dal nutrire contro il mondo l'odio escatologico dei donatisti e dal maledire e anatemizzare la natura alla maniera dei manichei" (V. GIORGIANNI, Il concetto del diritto, cit., IV.1, p. 111; cfr. anche IV.7).

${ }^{171}$ Cfr. J. RATZINGER, Die Einheit der Nationen, cit., 3.V, p. 115, nt. 3. "La sua civitas Dei non è una comunità puramente ideale di tutti gli uomini che credono in Dio, ma non ha neppure la minima comunanza con una teocrazia terrena, con un mondo costituito cristianamente, bensì è un'entità sacramentale-escatologica, che vive in questo mondo quale segno del mondo futuro" (J. RATZINGER, Die Einheit der Nationen, cit., 3.V, p. 113). Si badi che "[...] nell'elemento sacramentale secondo l'interpretazione di Agostino si presenta insieme anche quello escatologico: la Chiesa come communio caritatis rimane 'estranea' in questo mondo, essa non diviene 'Stato terreno', teocrazia, ma ha il suo fine nell' $\grave{\delta} \sigma \chi \alpha \tau o v$. In questo senso, la concezione sacramentale in Agostino serve a preservare l'elemento escatologico, non a distruggerlo" (J. RATZINGER, Die Einheit der Nationen, cit., 3.V, p. 113, nt. 1).

172 In particolare, l'identificazione tra la $C D$ e la Chiesa visibile: cosa che, come già visto (cfr. supra, par. 9), Agostino non effettua. Secondo Marrou, il primo ad avere parlato di un'unica città - invece che di due -, ossia della Chiesa, è Ottone di Frisinga nel XII secolo (cfr. H.-I. MARROU, Théologie de l'histoire, cit., I.5, p. 63): "L'errore ben preciso che si tratta di denunciare [...] era stato quello di identificare, o poco meno, la costruzione della città cristiana, e più precisamente all'interno di essa lo sviluppo della società spirituale che è la Chiesa visibile, con l'edificazione e il progresso, normalmente invisibili in misura ampia, della Città di Dio. Non bisogna rimproverare ai medievali [...] il progetto di costruire una città cristiana, ma piuttosto il fatto di aver confuso il mezzo con il fine, o più precisamente il fine subordinato con quello supremo [...]" (H.-I. MARROU, Théologie de l'histoire, cit., I.5, p. 63). 
rappresentare un punto di svolta nella riflessione circa il potere mondano:

"Generaliter quippe cuiuitas impiorum, cui non imperat Deus oboedienti sibi, ut sacrificium non offerat nisi tantummodo sibi, et per hoc in illa et animus corpori ratioque uitiis recte ac fideliter imperet, caret iustitiae ueritate" 173 .

Ora, di primo acchito potrebbe sembrare l'ennesima conferma che la CS - assieme alle sue concretizzazioni mondane - manchi della giustizia di Dio: ciò è sicuramente vero, ma va sottolineato, piuttosto, come Agostino riconosca, nella civitas impiorum, qualcosa che sfugge al controllo celeste, ossia che non soggiace all'obbedienza verso Dio. Ebbene, si tratta di una conclusione inevitabile, stante la radicale dicotomia tra le due civitates, ma ciò provoca anche un'emancipazione del potere mondano rispetto alla sfera divina. Infatti, se qualcosa è malvagio ed è, per di più, predestinato a essere tale, non ha alcun senso pretendere, da parte sua, l'osservanza dei comandamenti di Dio: quindi, la CS - assieme alle sue concretizzazioni mondane - può comportarsi come meglio crede, nell'esercizio delle sue attività secolari. Ecco fornito, astrattamente, l'impianto per l'attuazione di quella che sarà la progressiva emancipazione del potere civile da quello religioso, id est la secolarizzazione.

Per molti secoli, però, è come se la via alternativa prospettata nel libro XIX del $D c D$ fosse rimasta a un livello embrionale, senza una vera applicazione pratica. Si può dire, in altre parole, che i pensatori politici si siano tenuti fedeli all'Agostino del libro II e alla dottrina di una rigorosa predestinazione come motore di ogni aspetto della vita umana ${ }^{174}$.

Bisogna aspettare Dante Alighieri per assistere alla svolta: costui, nel Monarchia, fa assurgere l'Impero romano a modello di giustizia ${ }^{175}$; resta, comunque, il fatto che, con Dante, si attua il vero superamento del

\section{${ }_{173}$ Ciu., XIX, 24.}

174 Va detto che già nel pensiero di Ruggero Bacone si potrebbe ravvisare una svolta (cfr. É. GILSON, Les métamorphoses de la cité de Dieu, cit., III, pp. 113-144), ma in realtà, tra i due autori, non c'è una vera divergenza di fondo, in quanto ambedue, comunque, fondano i loro ragionamenti sulla questione della predestinazione (cfr. É. GILSON, Les métamorphoses de la cité de Dieu, cit., III, specialmente p. 141).

175 Cfr. É. GILSON, Les métamorphoses de la cité de Dieu, cit., IV, 158 ss., specialmente p. 162. Certamente, va considerato che il Poeta è mosso dall'esigenza di giustificare la non derivazione dell'Impero dalla Chiesa, per cui, se già nella Roma pagana c'era un potere legittimo, allora le origini dell'imperatore cristiano, successore di quello pagano, sono antecendenti (id est, indipendenti) alla Chiesa (cfr. É. GILSON, Les métamorphoses de la cité de Dieu, cit., IV, p. 173 s.). 
problema della predestinazione, in quanto, per la comunità dell'Impero, "[...] tutti sono chiamati, tutti sono eletti"176, sulla base del fatto che non è più richiesta una comunanza di fede - per quanto, anzi, l'adesione al cristianesimo non fosse indifferente -, bastando l'assoggettamento di ogni uomo alla ragione ${ }^{177}$. Dunque, si assiste all'abbandono del rapporto giustizia-Stati secondo la visione confessionista presente nel $D c D$, in favore della visione alternativa laica.

Ecco che, allora, l'Impero romano, già sdoganato da Agostino come tutti gli altri Stati, diviene qui una vera e propria manifestazione di diritto - cosa che l'Ipponense non avrebbe certamente potuto affermare, stante l'assenza in esso della giustizia di Cristo -: Dante, infatti, parte dal dato di fatto che l'Urbe è prevalsa su tutti gli altri popoli, nella competizione per il dominio del mondo; ebbene, ciò è stato possibile in forza di un divinum iudicium e, quindi, sempre in forza di un giudizio divino ha ottenuto l'Impero, il che equivale a dire che l'ha ottenuto de iure ${ }^{178}$. Il che, non più solo de facto, come implicitamente si limitava a registrare Agostino, bensì, con Dante, anche di diritto.

\section{2 - Una conseguenza imprevedibile (?): la secolarizzazione}

A ben guardare, però, sarebbe proprio la genesi dello Stato modernamente inteso a segnare il superamento dell'impianto principale agostiniano, in quanto risultano necessarie due condizioni: la concentrazione di un potere sovrano e la mondanizzazione degli scopi ${ }^{179}$. Il secondo aspetto altro non è che la questione della secolarizzazione e pare riconducibile, sul piano dei principî, alla lotta per le investiture ${ }^{180}$. Tale scontro ha un preciso

176 Cfr. É. GILSON, Les métamorphoses de la cité de Dieu, cit., IV, p. 178.

177 Cfr. É. GILSON, Les métamorphoses de la cité de Dieu, cit., IV, p. 179 s. Sul Monarchia e le sue implicazioni circa il rapporto tra sfera politica e sfera religiosa, cfr. anche G. AGAMBEN, Pilato e Gesù, Nottetempo, Milano, 2018 (nuova ed.), pp. 58-60, nrr. 15 s., e p. $80 \mathrm{~s}$.

178 Cfr. Monarchia, specialmente II, 8 (D. ALIGHIERI, Monarchia, a cura di G. VINAY, Sansoni, Firenze, 1950, pp. 158-166).

179 Cfr. E.-W. BÖCKENFÖRDE, Die Entstehung des Staates als Vorgang der Säkularisation (1967), in IDEM, Recht, Staat, Freiheit. Studien zur Rechtsphilosophie, Staatstheorie und Verfassungsgeschichte, Suhrkamp, Frankfurt a.M., 1991, traduzione italiana di C. BERTANI, La formazione dello Stato come processo di secolarizzazione, Morcelliana, Brescia, 2006, p. 33.

180 Cfr. E.-W. BÖCKENFÖRDE, Die Entstehung des Staates, cit., p. 35. Prima di allora "[l]' "Impero" non viveva dell'eredità degli imperatori romani, sebbene vi facesse 


\section{fondamento:}

«Il principio che rese internamente possibile questa lotta e che la portò al di là di una semplice contrapposizione tra potenze, in quanto gli prestò la sua fondazione spirituale, fu la separazione fra "spirituale" e "secolare"»181.

Seguendo lo svolgimento storico, si arriva alle divisioni confessionali derivanti dalla Riforma luterana ${ }^{182}$ : in particolare, giocano un ruolo di rilievo i giuristi francesi che, nel XVI secolo, difendono le prerogative dello Stato ${ }^{183}$, sino ad arrivare all'editto di Nantes (1598): "Il singolo poteva essere cittadino del regno, godere di tutti i diritti civili, senza appartenere alla vera religione. La prima, sostanziale separazione

riferimento, bensì della teologia della storia cristiana e dell'attesa della fine dei tempi: era l'Impero del populus christianus, forma fenomenica dell'ecclesia, e come tale era completamente coinvolto nel compito di realizzare il regnum Dei sulla terra e di respingere l'assalto del Male nell'eone presente (kat-echon)» (E.-W. BÖCKENFÖRDE, Die Entstehung des Staates, cit., I, p. 36 s.).

${ }^{181}$ E.-W. BÖCKENFÖRDE, Die Entstehung des Staates, cit., I, p. 38; cfr. anche p. 39. "La rivoluzione che si produsse in questo modo significò qualcosa di più di una desacralizzazione dell'imperatore. Assieme a lui anche l'ordinamento politico come tale venne licenziato dalla sfera sacrale e sacramentale; esso venne letteralmente desacralizzato e secolarizzato, e fu quindi posto sul suo proprio binario, libero di svilupparsi da sé come affare terreno. Ma grazie alla dialettica ineliminabile dei processi storici, ciò che si pensava fosse una svalorizzazione, al fine di rintuzzare le pretese imperiali nell'ambito dell'ecclesia, si trasformò in un'emancipazione: la lotta per le investiture fa della politica un ambito a sé stante; questa non è più capace, e non ha più bisogno, di una fondazione spirituale, ma di una laica, cioè giusnaturalistica" (E.-W. BÖCKENFÖRDE, Die Entstehung des Staates, cit., I, p. 39 s.). La conseguenza è radicale: "Con la stessa logica con cui l'agire mondano, ratione peccati, era stato posto sotto la competenza del potere spirituale, l'agire spirituale poteva ora, ratione ordinis publici, venir sottoposto alla competenza del potere temporale" (E.-W. BÖCKENFÖRDE, Die Entstehung des Staates, cit., I, p. 43).

${ }^{182}$ Cfr. E.-W. BÖCKENFÖRDE, Die Entstehung des Staates, cit., II, p. 45 ss.

183 "Questi politiques misero a punto una propria argomentazione, specificamente politica e nuova rispetto alla tradizione del diritto naturale scolastico. Essi stabilirono un concetto formale di pace, ricavato non dalla vita nella verità, ma dall'opposizione alla guerra civile. A questo concetto formale di pace, cioè al silenzio delle armi, alla quiete pubblica e alla sicurezza della vita, essi riconobbero il primato rispetto al conflitto per la verità religiosa. [...] Di contro al terrore e alle sofferenze propri della guerra civile, la pace formale è per i politiques un bene che si giustifica in sé. Essa può essere ottenuta solo tramite l'unità del paese; questa unità del paese è possibile solo attraverso il rispetto del comando del re, in quanto legge suprema; il re è l'istanza neutrale, posta al di sopra dei partiti e dei cittadini in lotta, solo lui può creare e mantenere la pace" (E.-W. BÖCKENFÖRDE, Die Entstehung des Staates, cit., II, p. 50 s.). 
tra Chiesa e Stato era così divenuta realtà"184. Ora, al di là della separazione tra Stato e Chiesa che - si è visto - è già un'acquisizione dell'originario pensiero di Agostino, figura come novità proprio questo: "L'Editto di Nantes fece per la prima volta il tentativo di ammettere due religioni in uno Stato" 185 .

Da questo momento in poi, la strada è 'in discesa', nel senso che gli Stati proseguono nel loro processo di secolarizzazione, con la tappa rilevante segnata dalla Rivoluzione francese ${ }^{186}$ :

"La sostanza dell'universale, che lo Stato deve incorporare e assicurare, non può più essere cercata nella religione, in una religione determinata, ma va trovata in obiettivi e interessi comuni di natura secolare, indipendenti dalla religione. La misura della realizzazione della libertà religiosa designa pertanto la misura della laicità [Weltlichkeit] dello Stato"187.

Significativamente, proprio in occasione dell'emancipazione definitiva dello Stato da qualsivoglia dimensione confessionista, si ripropone il tema del fondamento dell'autorità politica o, meglio, del suo inevitabile - operare sul piano etico ${ }^{188}$. Ecco, quindi, il paradosso:

${ }^{184}$ E.-W. BÖCKENFÖRDE, Die Entstehung des Staates, cit., II, p. 52.

185 E.-W. BÖCKENFÖRDE, Die Entstehung des Staates, cit., II, p. 52.

186 "La Rivoluzione francese portò a compimento quello Stato politico che era sorto nelle guerre civili confessionali e che era stato preconizzato da Hobbes" (E.-W. BÖCKENFÖRDE, Die Entstehung des Staates, cit., II, p. 59). Secondo il medesimo Autore, le acquisizioni della Rivoluzione francese sarebbero irreversibili: "Nessun percorso ci può riportare a prima della svolta del 1789 senza distruggere lo Stato, in quanto ordinamento della libertà" (E.-W. BÖCKENFÖRDE, Die Entstehung des Staates, cit., III, p. 69; cfr. anche II, pp. 61-63, in particolare: "Quando Carlo X di Francia eseguì l'imposizione delle mani sui lebbrosi, prescritta dalla cerimonia di incoronazione quale segno del divino potere taumaturgico dei re, egli indossava dei guanti" [E.-W. BÖCKENFÖRDE, Die Entstehung des Staates, cit., II, p. 62, nt. 41]).

${ }^{187}$ E.-W. BÖCKENFÖRDE, Die Entstehung des Staates, cit., II, p. 61.

188 «Ma è possibile fondare e conservare l'eticità in maniera del tutto terrena, secolare? Fondare lo Stato su una "morale naturale"? E se ciò non fosse possibile, lo Stato potrebbe vivere sulla sola base della soddisfazione delle aspettative eudaimonistiche dei suoi cittadini? Tutte queste domande ci riportano a una domanda più profonda, di principio: fino a che punto i popoli uniti in Stati possono vivere sulla base della sola garanzia della libertà, senza avere cioè un legame unificante che preceda tale libertà? [...] In un primo momento questo problema restò nell'ombra, in quanto nel diciannovesimo secolo una nuova forza unificante prese il posto della vecchia: l'idea di nazione. L'unità della nazione, subentrata a quella basata sulla religione, fondò una nuova omogeneità, che era di natura politica ed era diretta verso l'esterno. [...] Ma da allora l'idea di nazione ha perduto questa sua forza formale, e non solo in molti Stati europei» (E.-W. 


\begin{abstract}
"Lo Stato liberale [freiheitlich] secolarizzato vive di presupposti che non può garantire. Questo è il grande rischio che esso si è assunto per amore della libertà. Da una parte esso può esistere come Stato liberale solo se la libertà, che esso garantisce ai suoi cittadini, si regola dall'interno, cioè a partire dalla sostanza morale del singolo e dall'omogeneità della società. D'altra parte, però, se lo Stato cerca di garantire da sé queste forze regolatrici interne, cioè coi mezzi della coercizione giuridica e del comando autoritativo, esso rinuncia alla propria liberalità e ricade - su un piano secolarizzato - in quella stessa istanza di totalità da cui si era tolto con le guerre civili confessionali"189.
\end{abstract}

Insomma, sembrerebbe riemergere il tema del fondamento 'esterno' dell'autorità politica, nel senso di una riscoperta del contributo religioso per il funzionamento dello Stato ${ }^{190}$. Ora, al di là del fatto che non tutti condividono la tesi dei così detti presupposti non dimostrabili191, occorre tornare ad Agostino: costui, infatti, realisticamente riconosce che la teoria politica opera su una sorta di doppio binario.

Se, da un lato, non c'è dubbio che l'unico Stato giusto è lo Stato cristiano, dall'altro, bisogna riconoscere come gli uomini possano aggregarsi a prescindere anche da ogni minimo riferimento evangelico e formare, così, degli Stati. Detto altrimenti, l'attuale crisi di valori fondanti le comunità politiche, che sembrerebbe invocare il ritorno a una dimensione confessionista almeno blanda, risulta, secondo l'Ipponense, irrilevante. Come già visto, in base all'impianto del libro XIX del $D c D$, perché si possa avere una aggregazione politica basta che vi sia un (minimo) accordo condiviso tra i partecipanti e, dunque, ben potrebbe

BÖCKENFÖRDE, Die Entstehung des Staates, cit., III, p. 66 s.).

189 E.-W. BÖCKENFÖRDE, Die Entstehung des Staates, cit., III, p. 68 s. Per le diverse letture date del celebre detto (compresa l'interpretazione 'autentica' dell'Autore), cfr. M. NICOLETTI, Introduzione. Per amore della libertà. Lo Stato moderno e la coscienza, in E.-W. BÖCKENFÖRDE, Die Entstehung des Staates, cit., pp. 23-25.

190 «Così, ci sarebbe da chiedersi ancora una volta - con Hegel - se anche per lo Stato mondano secolarizzato, in ultima analisi, non sia necessario vivere degli impulsi e delle forze vincolanti che la fede religiosa trasmette ai suoi cittadini. Certo non nel senso che lo si riconfiguri di nuovo come Stato "cristiano", ma invece nel senso che i cristiani comprendano questo Stato, nella sua laicità, non più come qualcosa di estraneo e nemico della loro fede, bensì come l'opportunità della libertà, che è anche loro compito preservare e realizzare» (E.-W. BÖCKENFÖRDE, Die Entstehung des Staates, cit., III, p. 70).

191 "Al contrario di quanto assume Böckenförde, dunque, lo Stato democratico - mi sembra - è in grado di garantire da sé le premesse sulle quali si fonda" (M. LUCIANI, Sulla dottrina della democrazia in Benedetto XVI, in La legge di re Salomone, cit., p. 113). 
funzionare anche la peggior pax Babylonis'192; a ciò si aggiunga che le civitates impiorum sono abbandonate a se stesse, nel senso che non soggiacciono al comando di Dio e, dunque, possono legiferare e, più in generale, operare, come meglio ritengono.

Alla luce di ciò, per quanto cristianamente si possa e si debba stigmatizzare le condotte delle res publicae inique, bisogna anche ammettere che tali Stati non necessitano di alcuna fondazione esterna: ogni scelta politica, per quanto ingiusta, andrà bene, purché rientri nel patto di convivenza, che è l'unico criterio irrinunciabile per la sopravvivenza della comunità.

Si potrebbe pensare che quella di Agostino sia una posizione eccessivamente abdicante, rispetto al ruolo del cristianesimo nella società, ma, giova ricordarlo, tale soluzione consente anche di evitare il rischio che la CD possa venire identificata con una qualsiasi articolazione politica umana, come accadrebbe nel caso in cui uno Stato potesse vantare di aver collocato il Vangelo come proprio fondamento ${ }^{193}$.

A ogni modo, si badi che nemmeno la Chiesa terrena - affetta dal peccato al pari delle res publicae umane - può pretendere di essere la piena realizzazione della CD, in quanto soggetta anch'essa alla costante purificazione operata da Cristo, vera giustizia ${ }^{194}$.

192 Cfr. supra, par. 6. Contra Clark: "Few of us would agree that Augustine's second definition of a commonwealth which allows decadent Rome to be called one, namely, an association of rational beings united by a common love, aptly specifies a State; in fact, it could be used to cover any club or social organization" (M.T. CLARK, Augustine on justice, cit., p. 90).

193 "Il suo ineguagliabile risultato è di avere chiarito l'ambigua relazione del cristianesimo con l'ordine temporale e di avere stabilito, in opposizione ad alcuni dei più autorevoli scrittori cristiani dell'era di Costantino, la sua radicale trascendenza rispetto all'Impero romano e, quindi, a tutti i possibili regimi o ordinamenti politici" (E.L. FORTIN, Civitate Dei, De, cit., p. 408). Similmente, anche Barr afferma: "Saint Augustine never intended his City of God as anything but the mystical union of the good people of all nations. The understanding that the City of God is an accomplished fact - something real at this moment, and not some utopia elaborated as the last goal of political and social progress - would have forestalled attempts at its artificial realization in a purely temporal and political human society" (R.R. BARR, The Two Cities in Saint Augustine, cit., p. 228 s.).

194 Difficilmente, infatti, si potrebbe non applicare anche alla Chiesa terrena quanto osserva Clark in relazione alla definizione di res publica di cui in ciu., XIX, 24: "some historians have too hastily concluded that justice is not relevant to the second definition. Justice remains the norm for evaluating the true success of any State. What Augustine did was to rescue justice from identification with the law or "jus" of the individual nation, reveal the foundation of justice in God's eternal law, and thereby make clear its transcendent power to release the citizen from slavish subordination to the State. Above 


\section{3 - Conclusione}

Si è constatato come Agostino, nel $D c D$, operi un'evoluzione del proprio pensiero relativamente al concetto res publica: egli, infatti, abbandona la visione rigorosa per cui lo Stato, per essere tale, debba basarsi anche sul diritto - cioè su Cristo, vera giustizia -, in favore di un'idea più laica, per cui Stato può essere qualsivoglia aggregazione umana in cui vi sia concordia nella volontà dei sodali. Ciò non significa che l'Ipponense abdichi alla rilevanza del Vangelo nella sfera pubblica, bensì costituisce una constatazione di come, da sempre, anche gli Stati che più assomigliano a magna latrocinia restino in vita.

Res publica per eccellenza è la CD, la città degli eletti, cui si contrappone la CS, la città dei dannati; il tempo (saeculum) non è altro che la storia del rapporto tra queste due aggregazioni, ma l'effettiva appartenenza all'una piuttosto che all'altra città risulta imperscrutabile per gli uomini, in quanto solo Dio conosce il destino finale di ciascuno.

Centrale pare essere la questione dell'identificabilità della CD con la Chiesa: vi sono occorrenze testuali sia in senso affermativo che in senso negativo, ma è risultato possibile fornire una lettura sistematica tale per cui non c'è in Agostino una vera contraddizione, bensì una coesistenza di diverse finalità con conseguenti diversi punti di vista nell'analisi (quanto al tempo e quanto all'eternità).

In ogni caso, però, il vero criterio per distinguere i dannati dagli eletti è la predestinazione (non l'amor Dei/sibi, né il battesimo), la quale è totalmente imperscrutabile e indipendente dalle opere dell'uomo, poiché solo così la grazia di Dio resta gratuita.

In conclusione, si può notare come l'evoluzione della concezione di res publica abbia avuto una sensibile influenza sul processo di secolarizzazione dello Stato nel corso dei secoli, proprio per l'apertura alla mondanizzazione delle finalità politiche operata da Agostino nel libro XIX del $D c D$.

the State and its laws there is an Absolute to which rulers and citizens cannot rightly be opposed. Hence no citizen need obey an unjust law. The appeal is not merely to the subjective conscience but to the objective law of God as readable in human nature and as revealed in the Ten Commandments» (M.T. CLARK, Augustine on justice, cit., p. 90). 